\title{
The Origin of Magnetic Anisotropy and Single-molecule Magnet Behavior in Chromium(II)-based Extended Metal Atom Chains
}

Andrea Cornia, ${ }^{a *}$ Anne-Laure Barra, ${ }^{b}$ Vladimir Bulicanu, ${ }^{c}$ Rodolphe Clérac, ${ }^{c}$ Miguel Cortijo, ${ }^{c}$ Elizabeth A. Hillard, ${ }^{c *}$ Rita Galavotti, ${ }^{a}$ Alessandro Lunghi, ${ }^{d}$ Alessio Nicolini, ${ }^{a, e}$ Mathieu Rouzières, ${ }^{c}$ Lorenzo Sorace $e^{f}$ and Federico Totti ${ }^{f *}$

${ }^{a}$ Department of Chemical and Geological Sciences, University of Modena and Reggio Emilia \& INSTM, 41125 Modena, Italy

${ }^{b}$ Laboratoire National des Champs Magnétiques Intenses-CNRS, Université Grenoble-Alpes, 38042 Grenoble Cedex 9, France

${ }^{c}$ Univ. Bordeaux, CNRS, Centre de Recherche Paul Pascal, CRPP, UMR 5031, 33600 Pessac, France

${ }^{d}$ School of Physics, AMBER and CRANN Institute, Trinity College Dublin, Dublin 2, Ireland

${ }^{e}$ Department of Physics, Informatics and Mathematics, University of Modena and Reggio Emilia, 41125 Modena, Italy

${ }^{f}$ Department of Chemistry 'Ugo Schiff', University of Florence \& INSTM, 50019 Sesto Fiorentino (FI), Italy

\section{SUPPORTING INFORMATION}




\section{Synthesis}

General. Unless otherwise noted, reagents and solvents were of commercial origin and used without further purification. Naphthalene was resublimed and NaSCN was recrystallized from acetone before use. Dichloromethane and diethyl ether for the synthesis of $\mathbf{1 a} \cdot \mathrm{Et}_{2} \mathrm{O}$ were purified using an Inert Technologies solvent purification system. For the synthesis of $\mathbf{2 a} \cdot 4 \mathrm{CHCl}_{3} \cdot 2 \mathrm{Et}_{2} \mathrm{O}$ and $\mathbf{2} \mathbf{b}$ anhydrous dichloromethane (SigmaAldrich) was directly used, while chloroform was washed with water, stirred over $\mathrm{CaCl}_{2}$ overnight and distilled under $\mathrm{N}_{2}$; diethyl ether was pre-dried over $\mathrm{CaCl}_{2}$ overnight and distilled from its sodium benzophenone ketyl solution under $\mathrm{N}_{2} ; n$-hexane was dried over $4 \mathrm{~A}$ molecular sieves; all these solvents were degassed by three freeze-pump-thaw cycles. ${ }^{1}$ The $\mathrm{H}_{2}$ tpda ligand was prepared as described elsewhere, ${ }^{2,3}$ recrystallized from boiling methanol or 2-propanol and checked by ${ }^{1} \mathrm{H}$ NMR spectroscopy and melting point measurement. All reactions involving chromium(II) complexes were carried out under $\mathrm{Ar}$ or $\mathrm{N}_{2}$ atmosphere using Schlenk techniques or glovebox methods. Elemental analysis was carried out by Microlab Kolbe (Oberhausen, Germany, $\left.\mathbf{1 a} \cdot \mathrm{Et}_{2} \mathrm{O}\right)$ or on a Carlo Erba EA1110 CHNS-O automatic analyzer (2a-4 $\mathrm{CHCl}_{3} \cdot 2 \mathrm{Et}_{2} \mathrm{O}$ and $\left.\mathbf{2 b}\right)$. The IR spectra were measured on a Nicolet 6700 FT-IR spectrometer using a Smart iTR accessory between 600 and $4000 \mathrm{~cm}^{-1}$ with $4 \mathrm{~cm}^{-1}$ resolution $\left(\mathbf{1 a} \cdot \mathrm{Et}_{2} \mathrm{O}\right)$ or on a JASCO $4700 \mathrm{FT}$-IR spectrometer between 400 and $4000 \mathrm{~cm}^{-1}$ with $2 \mathrm{~cm}^{-1}$ resolution $\left(\mathbf{2 a} \cdot 4 \mathrm{CHCl}_{3} \cdot 2 \mathrm{Et}_{2} \mathrm{O}\right.$ and $\mathbf{2 b}$ ). Electrospray Ionization Mass Spectrometry (ESIMS) was performed on an Agilent Technologies 6310A Ion Trap LC-MS(n) spectrometer.

Synthesis of $\left[\mathrm{Cr}_{3}(\mathbf{d p a})_{4} \mathbf{C l}_{2}\right] \cdot \mathbf{E t}_{2} \mathrm{O}\left(\mathbf{1} \cdot \mathbf{E t} \mathbf{t}_{2} \mathrm{O}\right)$. Complex 1a was prepared following a literature procedure $^{4,5}$ and isolated as the monodiethylether solvate ${ }^{6,7}$ by layering a dichloromethane solution with diethyl ether, yielding a crop of dark green crystals in $60 \%$ yield after a week of diffusion. Anal. Calcd for $\mathrm{C}_{43.7} \mathrm{H}_{43.2} \mathrm{Cl}_{2.2} \mathrm{Cr}_{3} \mathrm{~N}_{12} \mathrm{O}_{1.9}\left(\mathbf{1 a} \cdot 0.9 \mathrm{Et}_{2} \mathrm{O} \cdot 0.1 \mathrm{CH}_{2} \mathrm{Cl}_{2} \cdot \mathrm{H}_{2} \mathrm{O}, 1000.87\right): \mathrm{C}, 52.44 ; \mathrm{H}, 4.35 ; \mathrm{N}, 16.79$. Found: C, 52.40; H, 4.19; N, 16.51. IR (ATR): $\tilde{v}_{\max }\left(\mathrm{cm}^{-1}\right) 1603 \mathrm{~m}, 1592 \mathrm{~s}, 1546 \mathrm{~m}, 1466 \mathrm{~m}, 1457 \mathrm{~m}, 1416 \mathrm{~s}, 1369 \mathrm{~m}, 1356 \mathrm{~m}$, 1310m, 1280w, 1153m, 1145m, 1103m, 1055w, 1011m, 917w, 882w, 857m, 767s, 752w, 741m, 701w, 690w, $644 \mathrm{~m}$. Unit cell parameters at $85 \mathrm{~K}$ were found consistent with those previously reported by Cotton, Murillo et al. at $213 \mathrm{~K}^{6}$ and by Overgaard, Iversen et al. at $100 \mathrm{~K}^{7}$ (see Table S1); structure solution and refinement confirmed that the crystalline material contains a minor fraction $(\sim 5-10 \%)$ of dichloromethane sharing the same crystallographic site with diethyl ether, as first noticed in Ref. ${ }^{7}$

Synthesis of $\left[\mathrm{Cr}_{5}(\mathrm{tpda})_{4} \mathrm{Cl}_{2}\right] \cdot 4 \mathrm{CHCl}_{3} \cdot \mathbf{2} \mathrm{Et}_{2} \mathrm{O}\left(2 \mathrm{a} \cdot \mathbf{4} \mathrm{CHCl}_{3} \cdot \mathbf{2} \mathrm{Et}_{2} \mathrm{O}\right)$. The compound was prepared in a glovebox starting from $\mathrm{H}_{2}$ tpda $(0.448 \mathrm{mmol}), \mathrm{CrCl}_{2}(0.672 \mathrm{mmol})$ and $t \mathrm{BuOK}(0.903 \mathrm{mmol})$ in refluxing naphthalene $(2.0 \mathrm{~g})$. We herein report the crystallization and sample collection procedures, which remain vague in the original paper by Peng et al.. ${ }^{8}$ After treating the cooled-down reaction mixture with $n$-hexane $(3 \times 15$ $\mathrm{mL})$ to remove naphthalene, the resulting brown solid was extracted with dichloromethane $(2 \times 10 \mathrm{~mL})$ yielding a dark-brown solution. The solvent was completely evaporated to give a bronze-colored solid, which was dissolved into the minimum amount of chloroform and the solution was filtered. Upon slow diffusion of diethyl ether vapors the compound crystallized as large, lustrous brown-black prisms that were easily separated from a $\tan$ powdery fraction by flotation in $\mathrm{Et}_{2} \mathrm{O}: \mathrm{CHCl}_{3} 5: 1 \mathrm{v} / \mathrm{v}$ ( $\sim 30 \%$ yield). Their composition, IR spectra 
and unit cell parameters (Table S1) were consistent with the compound first reported by Peng et al.. ${ }^{8}$ Anal. Calcd for $\mathrm{C}_{60} \mathrm{H}_{44} \mathrm{Cl}_{2} \mathrm{Cr}_{5} \mathrm{~N}_{20}$ (2a, 1376.01): C, 52.37; H, 3.22; N, 20.36. Found (crystals kept at 0.15 torr for 8 hours): C, 52.22; H, 3.29; N, 19.61. ESI-MS ( $\mathrm{CH}_{2} \mathrm{Cl}_{2}$ solution, direct infusion): $\mathrm{m} / z 1376.2\left([\mathrm{M}]^{+}, 100 \%\right)$. IR (crystals kept at 0.15 torr for 8 hours, $\mathrm{KBr}$ disk): $\tilde{v}_{\max }\left(\mathrm{cm}^{-1}\right) 1604 \mathrm{~m}, 1578 \mathrm{~m}, 1548 \mathrm{~m}, 1474 \mathrm{~m}, 1453 \mathrm{~m}, 1422 \mathrm{~s}$, 1408s, 1348m, 1335m, 1300w, 1263w, 1155m, 1007w, 772m, 736w.

Synthesis of $\left[\mathrm{Cr}_{5}(\mathbf{t p d a})_{4}(\mathbf{N C S})_{2}\right](\mathbf{2 b})$. To avoid use of water, the compound was prepared from $\mathbf{2 a} \cdot 4 \mathrm{CHCl}_{3} \cdot 2 \mathrm{Et}_{2} \mathrm{O}$ following the procedure described in Ref. ${ }^{9}$ rather than the original method in Ref. ${ }^{8}$ In a glovebox, 2a.4 $\mathrm{CHCl}_{3} \cdot 2 \mathrm{Et}_{2} \mathrm{O}(49 \mathrm{mg}, 0.024 \mathrm{mmol})$ was dissolved in $\mathrm{CHCl}_{3}(3 \mathrm{~mL})$ and treated with $\mathrm{NaSCN}$ (17.4 mg, $0.215 \mathrm{mmol}$ ) and additional $\mathrm{CHCl}_{3}(9 \mathrm{~mL})$. The mixture was stirred for three days to give a brown solution and a fine brown precipitate. The solvent was completely evaporated under reduced pressure and the solid extracted with $\mathrm{CH}_{2} \mathrm{Cl}_{2}(3 \mathrm{~mL})$. A small fraction of the solution was evaporated to dryness and the solid residue checked by IR spectroscopy, which showed the expected $\mathrm{C} \equiv \mathrm{N}$ stretching band of N-bound thiocyanate at $2035 \mathrm{~cm}^{-1} .^{8}$ Vapor diffusion of diethyl ether into the filtered extracts afforded brown-black prisms which were washed with $\mathrm{Et}_{2} \mathrm{O}: \mathrm{CH}_{2} \mathrm{Cl}_{2}$ 5:1 v/v ( 30\% yield). Their composition and unit cell parameters (Table S1) were consistent with the compound first reported by Peng et al.. ${ }^{8}$ Anal. Calcd for $\mathrm{C}_{62} \mathrm{H}_{44} \mathrm{Cr}_{5} \mathrm{~N}_{22} \mathrm{~S}_{2}$ (2b, 1421.27): C, 52.40; H, 3.12; N, 21.68; S, 4.51. Found (crystals kept at 0.2 torr for 6 hours): C, 52.75; H, 2.92; N, 21.54; $\mathrm{S}, 4.36$. IR (crystals kept at 0.15 torr for 8 hours, ATR): $\tilde{v}_{\max }\left(\mathrm{cm}^{-1}\right) 2029 \mathrm{~m}, 1602 \mathrm{~m}, 1575 \mathrm{~m}, 1545 \mathrm{~m}, 1470 \mathrm{~m}$, $1451 \mathrm{~m}, 1404 \mathrm{~s}, 1333 \mathrm{~m}, 1297 \mathrm{w}, 1258 \mathrm{w}, 1152 \mathrm{~m}, 1007 \mathrm{w}, 764 \mathrm{w}, 731 \mathrm{w}$. 


\section{Structural characterization}

Table S1. Unit cell parameters obtained for known crystal phases investigated in this work.

\begin{tabular}{lccccccccc}
\hline compound & $T(\mathrm{~K})$ & $a(\AA)$ & $b(\AA)$ & $c(\AA)$ & $\alpha\left({ }^{\circ}\right)$ & $\beta\left(^{\circ}\right)$ & $\gamma\left({ }^{\circ}\right)$ & $V\left(\AA^{3}\right)$ & $\begin{array}{c}\text { Bravais } \\
\text { lattice }\end{array}$ \\
$\mathbf{1 a} \cdot \mathrm{Et}_{2} \mathrm{O}^{a}$ & 85 & $16.0384(5)$ & $15.7660(5)$ & $16.9975(5)$ & 90 & $98.847(1)$ & 90 & $4246.9(2)$ & $m P$ \\
$\mathbf{2 a} \cdot 4 \mathrm{CHCl}_{3} \cdot 2 \mathrm{Et}_{2} \mathrm{O}^{b}$ & 298 & $28.51(2)$ & $14.04(1)$ & $25.08(2)$ & 90 & $122.90(2)$ & 90 & $8429(11)$ & $m C$ \\
$\mathbf{2 b}^{b}$ & 298 & $10.782(8)$ & $10.782(8)$ & $26.15(2)$ & 90 & 90 & 90 & $3040(4)$ & $t I$ \\
\hline
\end{tabular}

${ }^{a}$ Bruker Quazar SMART APEXII diffractometer (Mo-K $\alpha$ radiation). ${ }^{b}$ Bruker-Nonius X8APEX four-circle diffractometer (Mo-K $\alpha$ radiation).

Table S2. Crystal data and structure refinement for $\mathbf{1 b} \cdot 0.4 \mathrm{CH}_{2} \mathrm{Cl}_{2}$.

\begin{tabular}{|c|c|c|}
\hline Molecular formula & \multicolumn{2}{|c|}{$\mathrm{C}_{42.40} \mathrm{H}_{32.80} \mathrm{Cl}_{0.80} \mathrm{Cr}_{3} \mathrm{~N}_{14} \mathrm{~S}_{2}$} \\
\hline Formula weight & \multicolumn{2}{|l|}{986.90} \\
\hline Temperature $(\mathrm{K})$ & \multicolumn{2}{|l|}{$120(2)$} \\
\hline Wavelength $(\AA)$ & \multicolumn{2}{|l|}{0.71073} \\
\hline Crystal system & \multicolumn{2}{|l|}{ monoclinic } \\
\hline Space group & \multicolumn{2}{|l|}{$C 2 / c($ No. 15$)$} \\
\hline \multirow[t]{3}{*}{ Unit cell dimensions $\left(\AA,^{\circ}\right)$} & $a=62.348(3)$ & $\alpha=90$ \\
\hline & $b=15.4922(7)$ & $\beta=106.305(2)$ \\
\hline & $c=23.0405(11)$ & $\gamma=90$ \\
\hline Unit cell volume $\left(\AA^{3}\right)$ & \multicolumn{2}{|l|}{$21360.1(17)$} \\
\hline$Z$ & \multicolumn{2}{|l|}{20} \\
\hline Calculated density $\left(\mathrm{Mg} / \mathrm{m}^{3}\right)$ & \multicolumn{2}{|l|}{1.534} \\
\hline Absorption coefficient $\left(\mathrm{mm}^{-1}\right)$ & \multicolumn{2}{|l|}{0.948} \\
\hline$F(000)$ & \multicolumn{2}{|l|}{10056} \\
\hline Crystal size $\left(\mathrm{mm}^{3}\right)$ & \multicolumn{2}{|c|}{$0.345 \times 0.175 \times 0.074$} \\
\hline Theta range for data collection $\left({ }^{\circ}\right)$ & \multicolumn{2}{|l|}{1.664 to 25.423} \\
\hline Index ranges & \multicolumn{2}{|c|}{$-70 \leq h \leq 75,-18 \leq k \leq 18,-27 \leq l \leq 27$} \\
\hline Reflections collected/independent & \multicolumn{2}{|c|}{$149744 / 19669[R(\mathrm{int})=0.1099]$} \\
\hline Completeness to theta $=25.423^{\circ}$ & \multicolumn{2}{|l|}{$99.7 \%$} \\
\hline Absorption correction & \multicolumn{2}{|c|}{ semi-empirical from equivalents } \\
\hline Max. and min. transmission & \multicolumn{2}{|l|}{0.7452 and 0.6846} \\
\hline Refinement method & \multicolumn{2}{|c|}{ Full-matrix least-squares on $F^{2}$} \\
\hline Data / restraints / parameters & \multicolumn{2}{|l|}{$19669 / 3 / 1414$} \\
\hline Goodness-of-fit on $F^{2}$ & \multicolumn{2}{|l|}{1.025} \\
\hline Final $R$ indices $[I>2 \sigma(I)]$ & \multicolumn{2}{|c|}{$R_{1}=0.0634^{a}, w R_{2}=0.1318^{b}$} \\
\hline$R$ indices (all data) & \multicolumn{2}{|c|}{$R_{1}=0.1180^{a}, w R_{2}=0.1546^{b}$} \\
\hline
\end{tabular}


Table S3. Continuous Shape Measures ${ }^{10}$ for terminal ions in chromium(II)-based EMACs with different nuclearity $(n)$ and axial ligands $(\mathrm{X})$.

\begin{tabular}{|c|c|c|c|c|c|c|}
\hline compound & $n$ & $X$ & $T(\mathrm{~K})$ & $\mathrm{vOC}-5^{a, b}$ & SPY $-5^{a, c}$ & Ref. $^{d}$ \\
\hline $\mathbf{1 a} \cdot \mathrm{Et}_{2} \mathrm{O}$ & 3 & $\mathrm{Cl}^{-}$ & 213 & $1.136(\mathrm{Cr} 1), 1.110(\mathrm{Cr} 3)$ & $0.459(\mathrm{Cr} 1), 0.513(\mathrm{Cr} 3)$ & 6 \\
\hline $\mathbf{1 b} \cdot 0.4 \mathrm{CH}_{2} \mathrm{Cl}_{2}$ & 3 & $\mathrm{SCN}^{-}$ & 120 & $\begin{array}{c}0.328 \text { (Cr1), } 0.336 \text { (Cr3), } \\
0.318 \text { (Cr4), } 0.325 \text { (Cr6), } \\
0.289(\mathrm{Cr} 7)\end{array}$ & $\begin{array}{c}0.777 \text { (Cr1), } 0.628 \text { (Cr3), } \\
0.694 \text { (Cr4), 0.699 (Cr6), } \\
0.737 \text { (Cr7) }\end{array}$ & $\begin{array}{c}\text { this } \\
\text { work }\end{array}$ \\
\hline $\mathbf{2 a} \cdot 4 \mathrm{CHCl}_{3} \cdot 2 \mathrm{Et}_{2} \mathrm{O}$ & 5 & $\mathrm{Cl}^{-}$ & 213 & $1.130(\mathrm{Cr} 1)$ & $0.303(\mathrm{Cr} 1)$ & 11 \\
\hline $2 b$ & 5 & $\mathrm{SCN}^{-}$ & RT & $0.317(\mathrm{Cr} 1)$ & $0.674(\mathrm{Cr} 1)$ & 8 \\
\hline
\end{tabular}

${ }^{a}$ Deviation between real and ideal coordination polyhedron. ${ }^{b}$ Vacant octahedron (Johnson square pyramid, J1). ${ }^{c}$ Square pyramid. ${ }^{d}$ From which atomic coordinates have been taken.

\section{Magnetic characterization}

Sample preparation. Samples for magnetic measurements were prepared with strict exclusion of dioxygen and moisture in a glovebox. Freshly-filtered polycrystalline samples of $\mathbf{1 a} \cdot \mathrm{Et}_{2} \mathrm{O}(15.11 \mathrm{mg})$ and $\mathbf{1 b} \cdot 0.4 \mathrm{CH}_{2} \mathrm{Cl}_{2}$ $(17.90 \mathrm{mg})$, unsolvated complex $\mathbf{2 a}\left(6.44 \mathrm{mg}\right.$, obtained by prolonged vacuum treatment of $\left.\mathbf{2 a} \cdot 4 \mathrm{CHCl}_{3} \cdot 2 \mathrm{Et}_{2} \mathrm{O}\right)$ and vacuum-dried crystals of $\mathbf{2 b}(6.0 \mathrm{mg})$ were covered with Paratone ${ }^{\circledR}$ oil (typically 10-20 $\mathrm{mg}$ ) to avoid magnetic torqueing and introduced in a sealed polyethylene bag $(3 \times 0.5 \times 0.02 \mathrm{~cm}$; typically $24-32 \mathrm{mg})$. Solvated crystals of $\mathbf{2 a} \cdot 4 \mathrm{CHCl}_{3} \cdot 2 \mathrm{Et}_{2} \mathrm{O}$, covered and restrained in a minimum amount of frozen mother liquor $(17.23 \mathrm{mg})$ within a sealed straw, were also measured for comparison. No evaporation of the mother liquor was observed during the measurements. The mass of the sample was estimated at about $13.2 \mathrm{mg}$ after the measurements and right after the mother liquor removal/evaporation (about 5 minutes) under Ar. It is worth noting that under the microscope the crystals looked perfectly shiny and crystalline immediately after removal of the mother liquor. Nevertheless, because residual solvent could easily alter the mass of the sample, the actual mass was accurately determined $(11.35 \mathrm{mg})$ by comparing the high-temperature magnetic data with those of the dry compound. Prior to the experiments, the field-dependent magnetization was measured at $100 \mathrm{~K}$ on each sample to exclude the presence of bulk ferromagnetic impurities.

Spin Hamiltonian calculations. Spin Hamiltonian calculations were carried out using in-house developed software in FORTRAN language based on F02ABF and E04FCF NAG routines for matrix diagonalization and least-square fitting, respectively. ${ }^{12}$ The zero-field splitting plus Zeeman Hamiltonian in Eq. (1) was used to fit isothermal magnetization vs. field data using isotropic $g, D$ and, occasionally, a preferential orientation coefficient $a_{2}$ and/or a scale factor as adjustable parameters. Preferential orientation effects were modelled with an axial probability function ${ }^{13}$ expressed as a linear combination of Legendre polynomials of even order, including only $P_{0}(\cos \theta)=1$ and $P_{2}(\cos \theta)=\left(3 \cos ^{2} \theta-1\right) / 2$. The value of $a_{0}$ is fixed by the normalization condition, while a positive/negative value of $a_{2}$ indicates a prolate/oblate distribution of the easy axes, respectively, i.e. the "parallel" arrangement is more/less populated than in a randomly-oriented sample. The need for introducing preferential orientation was already encountered in the past in our 
laboratories and shown to arise from a non statistical distribution of crystal orientations in samples comprising a small number of large crystals, and not from field-induced torqueing. The estimated standard deviations of best-fit parameters, quoted in Tables 2 and S4, were calculated from the variances of the regression coefficients, as provided by routine E04YCF. ${ }^{12}$

Table S4. Magnetic parameters of chromium(II)-based EMACs with different nuclearity $(n)$ and axial ligands $(\mathrm{X})$, as determined by dc magnetic measurements (isothermal magnetization vs. field).

\begin{tabular}{lccccccc}
\hline compound & $n$ & $\mathrm{X}$ & $S$ & $g$ & $D\left(\mathrm{~cm}^{-1}\right)$ & $a_{2}$ & scale factor \\
$\mathbf{1 a} \cdot \mathrm{Et}_{2} \mathrm{O}$ & 3 & $\mathrm{Cl}^{-}$ & $2^{a}$ & $1.957(2)$ & $-1.656(16)$ & $0.067(2)$ & $1.000^{a}$ \\
$\mathbf{1 b} \cdot 0.4 \mathrm{CH}_{2} \mathrm{Cl}_{2}$ & 3 & $\mathrm{SCN}^{-}$ & $2^{a}$ & $2.0360(17)$ & $-1.711(12)$ & $-0.0312(15)$ & $1.000^{a}$ \\
$\mathbf{2 a} \cdot 4 \mathrm{CHCl}_{3} \cdot 2 \mathrm{Et}_{2} \mathrm{O}$ & 5 & $\mathrm{Cl}^{-}$ & $2^{a}$ & $1.9774(3)$ & $-1.507(2)$ & $-0.1501(3)$ & $1.000^{a}$ \\
$\mathbf{2 a}$ & 5 & $\mathrm{Cl}^{-}$ & $2^{a}$ & $1.9731(8)$ & $-1.510(6)$ & $0.000^{a}$ & $1.000^{a}$ \\
$\mathbf{2 b}$ & 5 & $\mathrm{SCN}^{-}$ & $2^{a}$ & $1.985^{a}$ & $-1.696(4)$ & $0.0889(4)$ & $0.9247(3)$ \\
\hline
\end{tabular}

${ }^{a}$ Parameter held fixed. 


\subsection{Magnetic data for $\left[\mathrm{Cr}_{3}(\mathrm{dpa})_{4} \mathrm{Cl}_{2}\right] \cdot \mathrm{Et}_{2} \mathrm{O}\left(1 \mathrm{a} \cdot \mathrm{Et}_{2} \mathrm{O}\right)$}

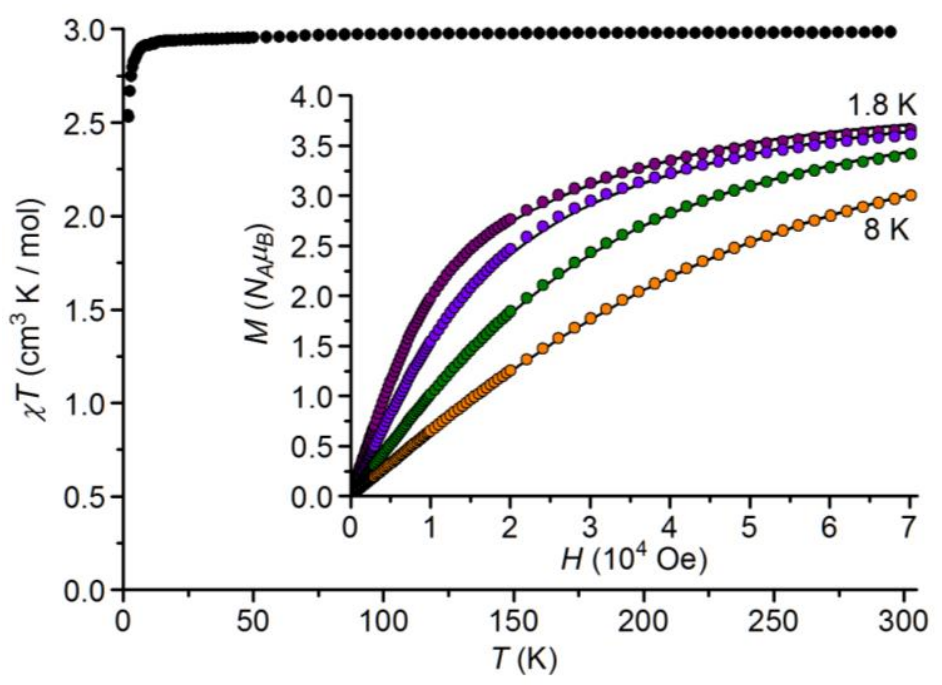

Figure S1. $\chi T$ vs. $T$ plot for $1 \mathbf{a} \cdot \mathrm{Et}_{2} \mathrm{O}$ in the temperature range $1.85-295 \mathrm{~K}$ at $1 \mathrm{kOe}$. At room temperature, the $\chi T$ product is $2.98 \mathrm{~cm}^{3} \mathrm{~K} \mathrm{~mol}^{-1}$. When the temperature is lowered, the $\chi T$ product decreases reaching $2.54 \mathrm{~cm}^{3} \mathrm{~K} \mathrm{~mol}^{-1}$ at $1.85 \mathrm{~K}$. The inset presents $M$ vs. $H$ data measured at four different temperatures (1.8, 3.0, 5.0 and 8.0 K), along with the best-fit curves to the 452 data points with the parameters reported in the text.

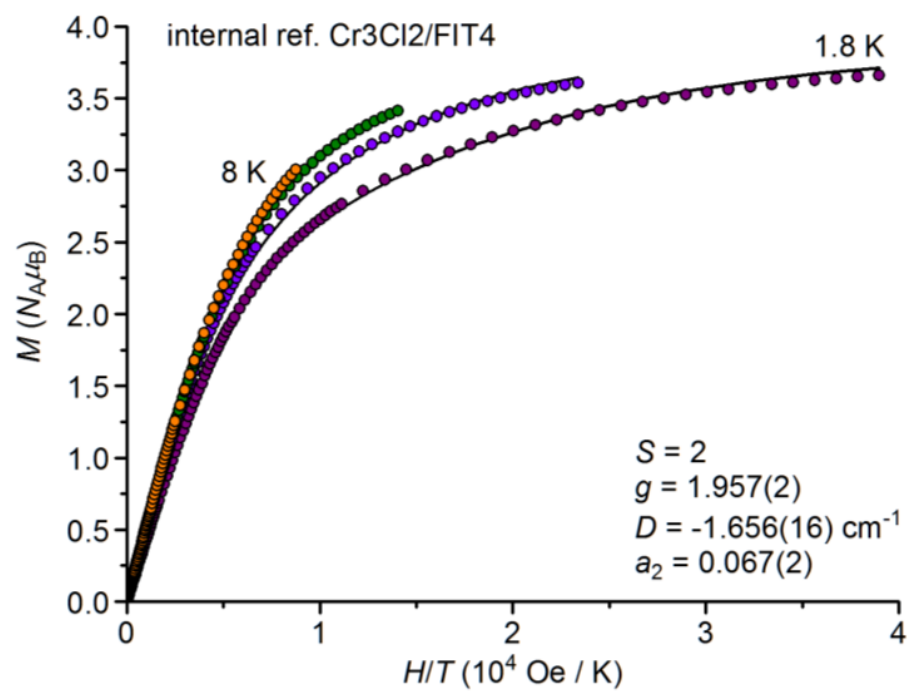

Figure S2. $M$ vs. $H / T$ plot for $\mathbf{1 a} \cdot \mathrm{Et}_{2} \mathrm{O}$ at four different temperatures $(1.8,3.0,5.0$ and $8.0 \mathrm{~K})$, along with the best-fit curves to the 452 data points with the parameters reported in the text. 

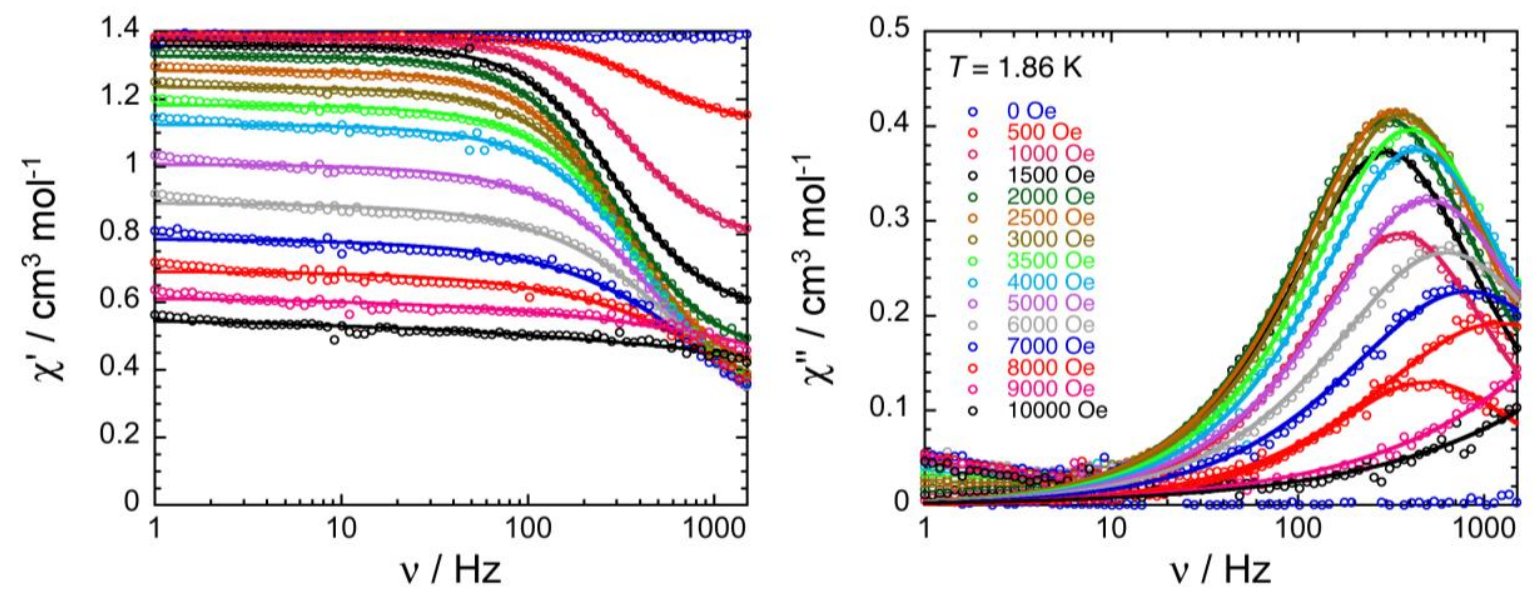

Figure S3. In-phase (left) and out-of-phase (right) components of the molar ac magnetic susceptibility of 1a.Et $\mathrm{o}_{2} \mathrm{O}$ measured at $1.86 \mathrm{~K}$ as a function of applied dc field between 0 and $10 \mathrm{kOe}$. The solid curves on the figures provide the best fit using the generalized Debye model.
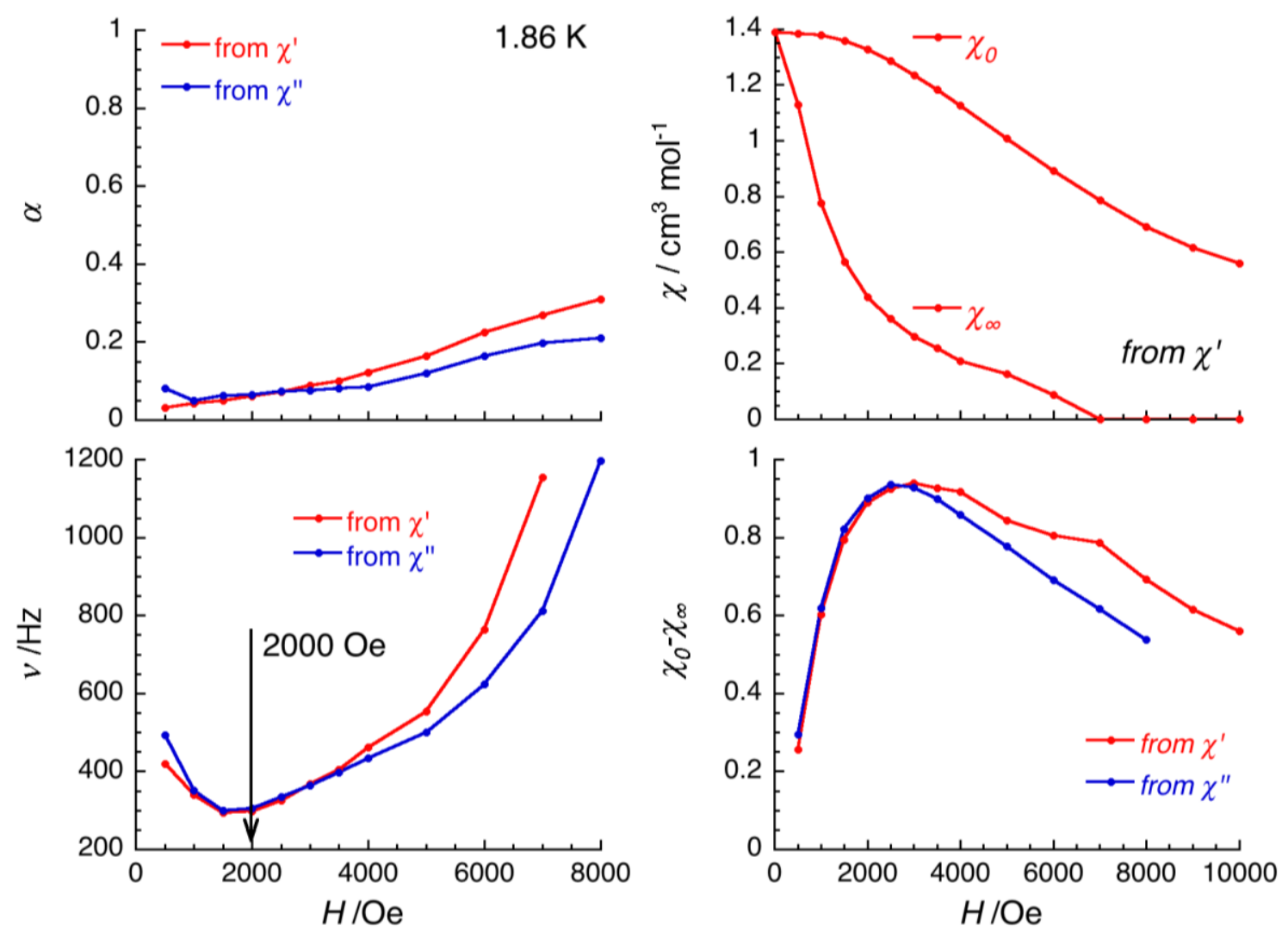

Figure S4. Field dependence of the parameters $\alpha, v, \chi_{0}, \chi_{\infty}$ and $\chi_{0}-\chi_{\infty}$ between 0 and $10 \mathrm{kOe}$ deduced from the generalized Debye fit of the frequency dependence of the real $\left(\chi^{\prime}\right)$ and imaginary $\left(\chi^{\prime \prime}\right)$ components of the ac susceptibility at $1.86 \mathrm{~K}$, shown in Figure S3, for $\mathbf{1 a} \cdot \mathrm{Et}_{2} \mathrm{O}$. The slowest relaxation occurs at $2.0 \mathrm{kOe}$. 

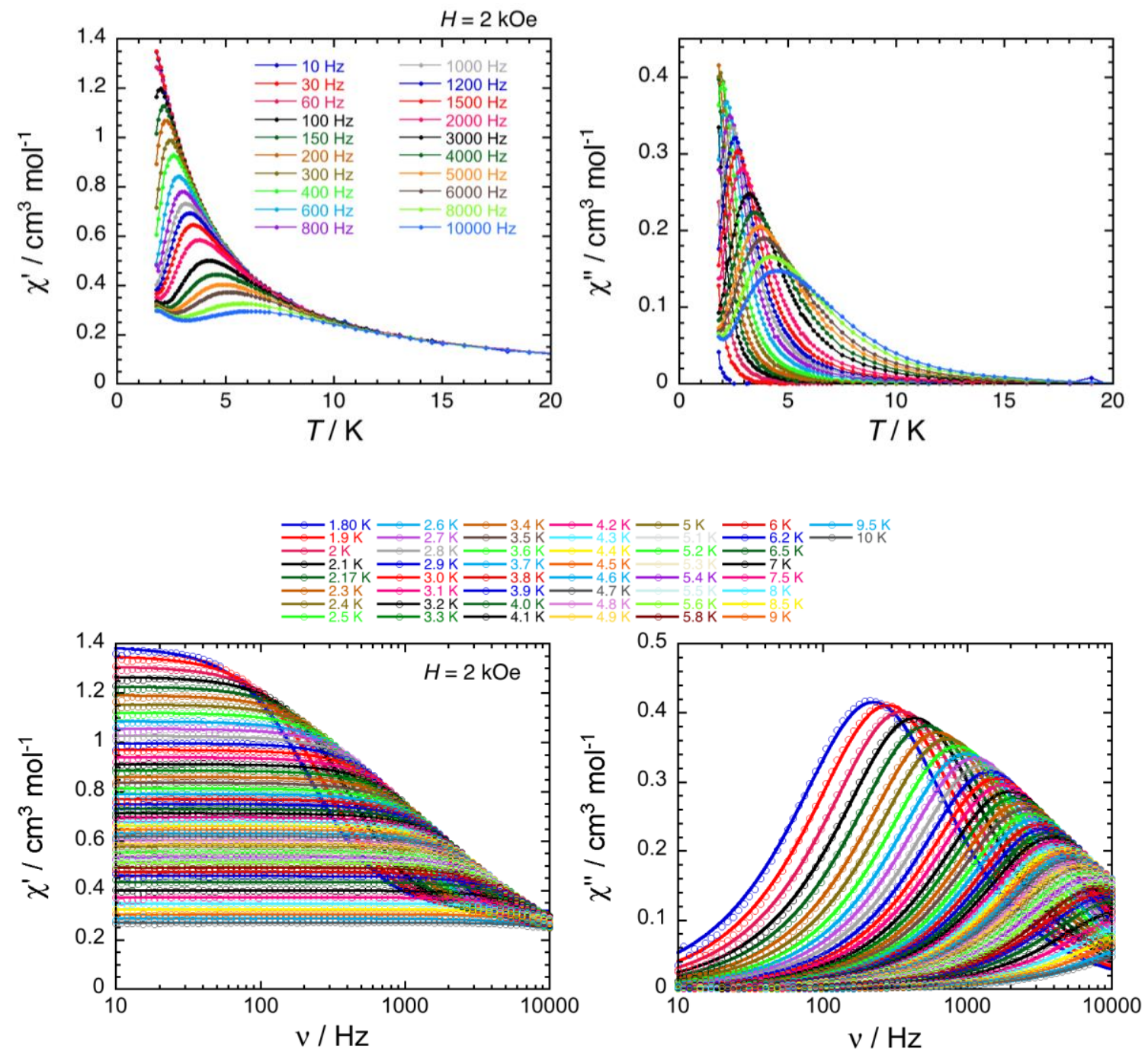

Figure S5. In-phase (left) and out-of-phase (right) components of the molar ac magnetic susceptibility of 1a·Et $2 \mathrm{O}$ measured as a function of temperature at different frequencies (top) and as a function of frequency at different temperatures (bottom) at $2.0 \mathrm{kOe}$. While solid lines on the top figures are visual guides, the solid curves on the bottom figures provide the best fit using the generalized Debye model. 

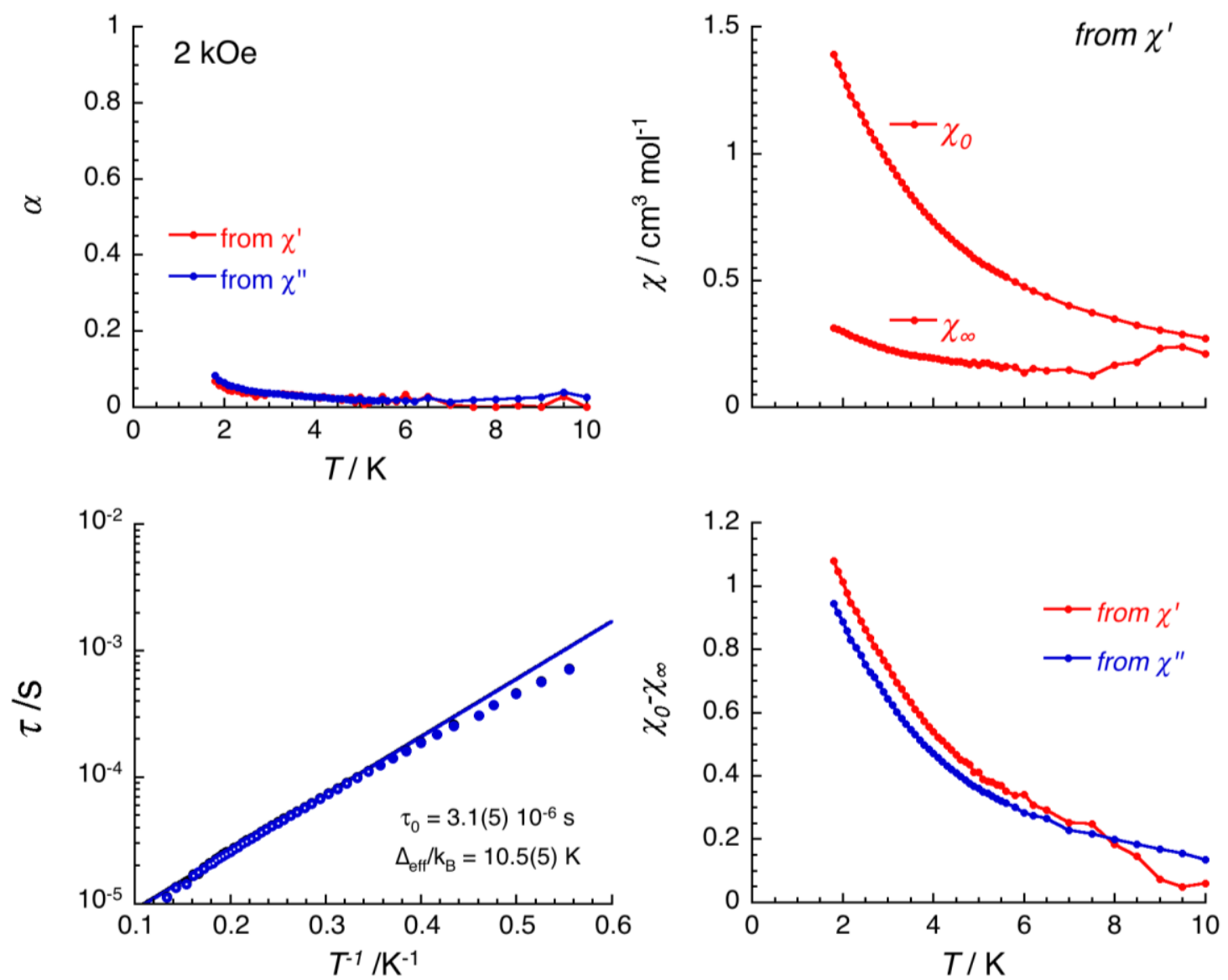

Figure S6. Temperature dependence of the parameters $\alpha, \tau, \chi_{0}, \chi_{\infty}$ and $\chi_{0}-\chi_{\infty}$ between 1.8 and $10 \mathrm{~K}$ deduced from the generalized Debye fit of the frequency dependence of the real $\left(\chi^{\prime}\right)$ and imaginary $\left(\chi^{\prime \prime}\right)$ components of the ac susceptibility at $2.0 \mathrm{kOe}$, shown in Figure S5, for $\mathbf{1 a} \cdot \mathrm{Et}_{2} \mathrm{O}$. On the bottom left figure, the temperature dependence of the relaxation time of $1 \mathrm{a} \cdot \mathrm{Et}_{2} \mathrm{O}$ at $2.0 \mathrm{kOe}$ between 1.8 and $7.5 \mathrm{~K}$ (treatment of $\chi^{\prime}$ vs. $v$ and $\chi^{\prime \prime}$ vs. $v$ curves gives indistinguishable results; both sets of data are plotted). The solid line provides the best fit Arrhenius law to the data represented with hollow points with the reported parameter set. 
3.2 Magnetic data for $\left[\mathrm{Cr}_{3}(\mathrm{dpa})_{4}(\mathrm{NCS})_{2}\right] \cdot 0.4 \mathrm{CH}_{2} \mathrm{Cl}_{2}\left(\mathbf{1 b} \cdot 0.4 \mathrm{CH}_{2} \mathrm{Cl}_{2}\right)$

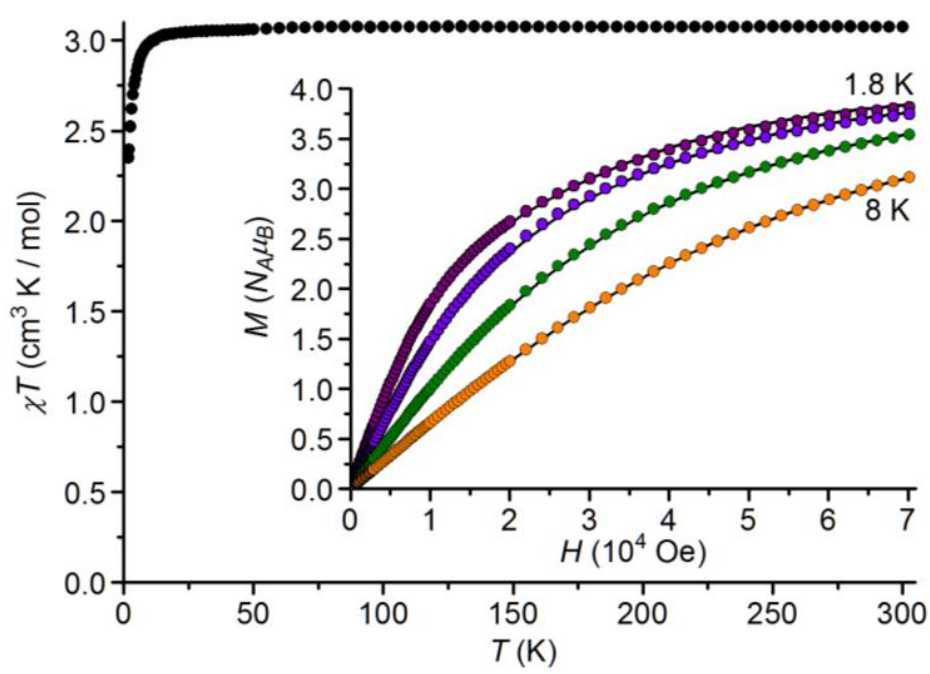

Figure S7. $\chi T$ vs. $T$ plot for $1 \mathbf{b} \cdot 0.4 \mathrm{CH}_{2} \mathrm{Cl}_{2}$ in the temperature range $1.85-300 \mathrm{~K}$ at $1 \mathrm{kOe}$. At room temperature, the $\chi T$ product is $3.08 \mathrm{~cm}^{3} \mathrm{~K} \mathrm{~mol}^{-1}$. When the temperature is lowered, the $\chi T$ product decreases reaching $2.35 \mathrm{~cm}^{3} \mathrm{~K} \mathrm{~mol}^{-1}$ at $1.85 \mathrm{~K}$. The inset presents $M$ vs. $H$ data measured at four different temperatures $(1.8,3.0,5.0$ and $8.0 \mathrm{~K})$, along with the best-fit curves to the 452 data points with the parameters reported in the text.

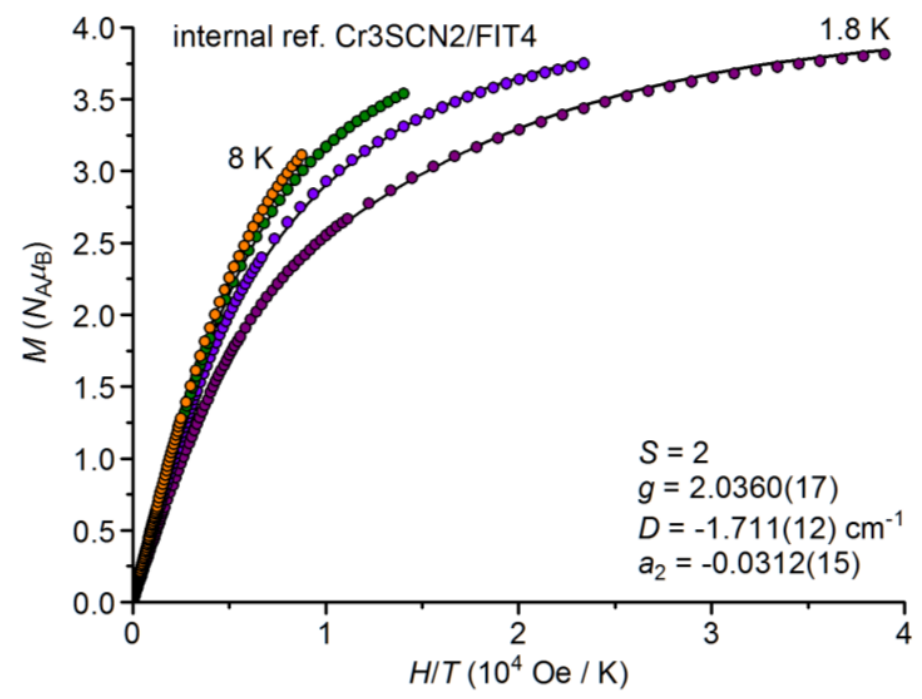

Figure S8. $M$ vs. $H / T$ plot for $\mathbf{1 b} \cdot 0.4 \mathrm{CH}_{2} \mathrm{Cl}_{2}$ at four different temperatures $(1.8,3.0,5.0$ and $8.0 \mathrm{~K})$, along with the bestfit curves to the 452 data points with the parameters reported in the text. 

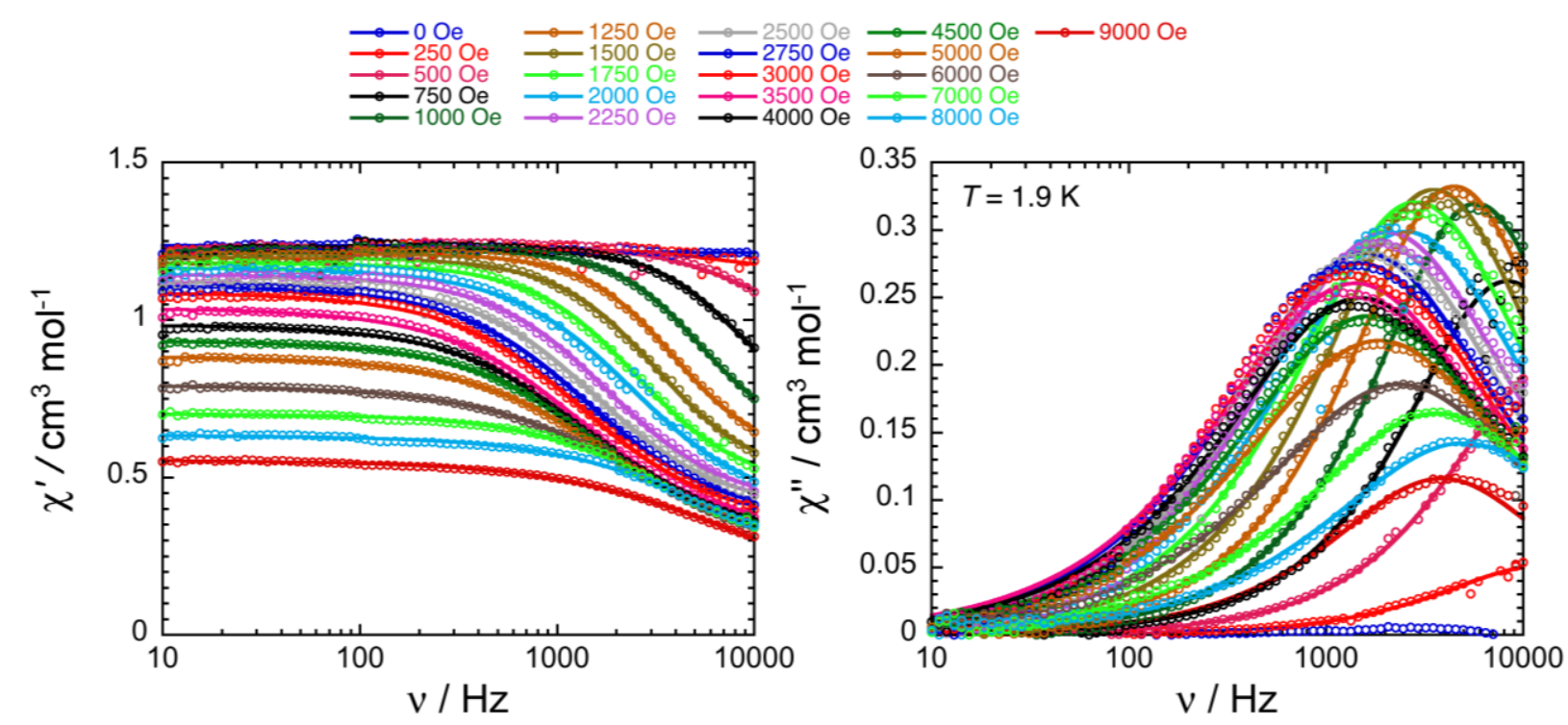

Figure S9. In-phase (left) and out-of-phase (right) components of the molar ac magnetic susceptibility of $\mathbf{1 b} \cdot 0.4 \mathrm{CH}_{2} \mathrm{Cl}_{2}$ measured at $1.9 \mathrm{~K}$ as a function of applied dc field between 0 and $9 \mathrm{kOe}$. The solid curves on the figures provide the best fit using the generalized Debye model.
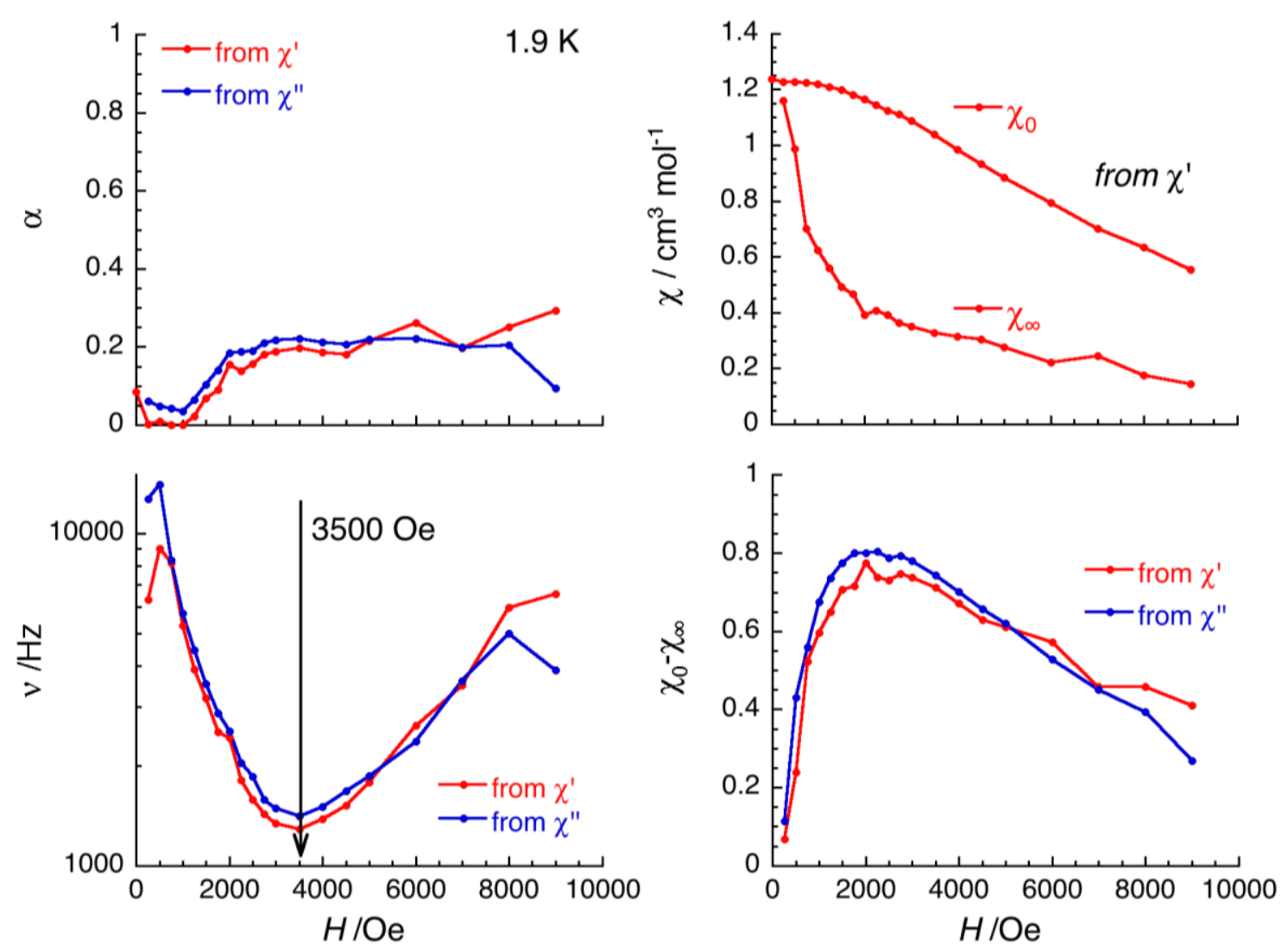

Figure S10. Field dependence of the parameters $\alpha, v, \chi_{0}, \chi_{\infty}$ and $\chi_{0}-\chi_{\infty}$ between 0 and 9 kOe deduced from the generalized Debye fit of the frequency dependence of the real $\left(\chi^{\prime}\right)$ and imaginary $\left(\chi^{\prime \prime}\right)$ components of the ac susceptibility at $1.9 \mathrm{~K}$, shown in Figure $\mathrm{S}$, for $\mathbf{1 b} \cdot 0.4 \mathrm{CH}_{2} \mathrm{Cl}_{2}$. The slowest relaxation occurs at $3.5 \mathrm{kOe}$. 

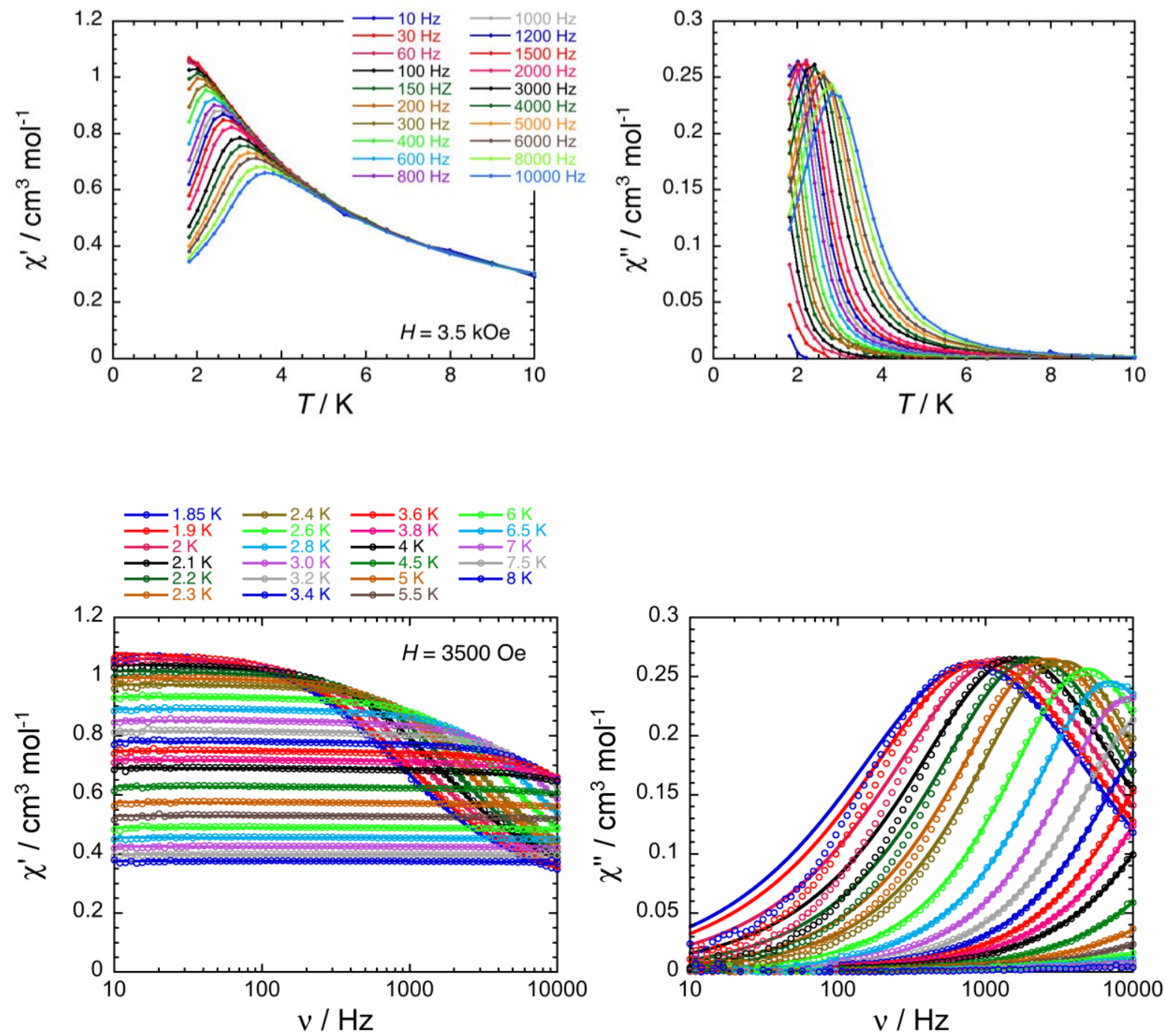

Figure S11. In-phase (left) and out-of-phase (right) components of the molar ac magnetic susceptibility of $\mathbf{1 b} \cdot 0.4 \mathrm{CH}_{2} \mathrm{Cl}$ measured as a function of temperature at different frequencies (top) and as a function of frequency at different temperatures (bottom) at $3.5 \mathrm{kOe}$. While solid lines on the top figures are visual guides, the solid curves on the bottom figures provide the best fit using the generalized Debye model. 

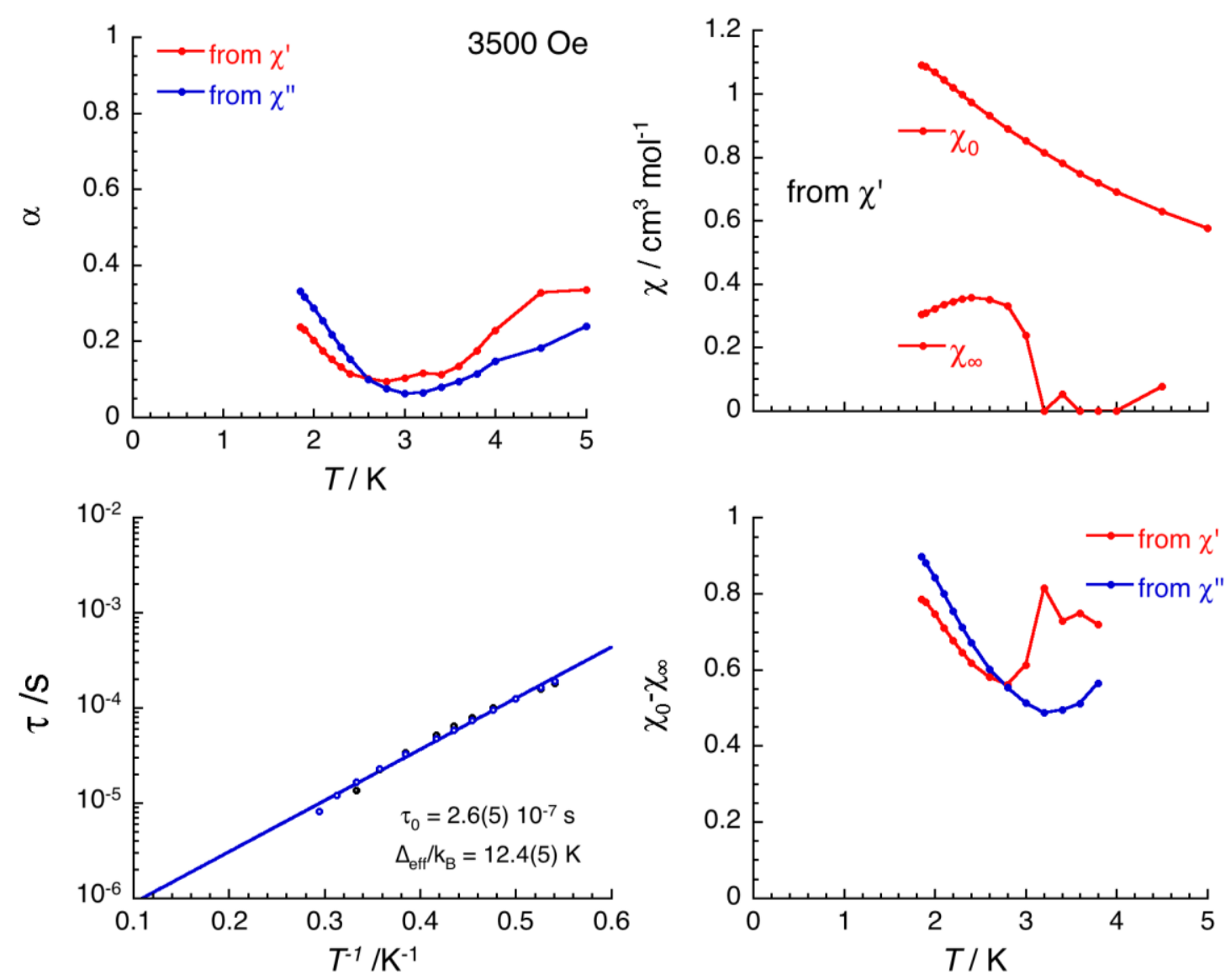

Figure S12. Temperature dependence of the parameters $\alpha, \tau, \chi_{0}, \chi_{\infty}$ and $\chi_{0}-\chi_{\infty}$ between 1.85 and $5 \mathrm{~K}$ deduced from the generalized Debye fit of the frequency dependence of the real $\left(\chi^{\prime}\right)$ and imaginary $\left(\chi^{\prime \prime}\right)$ components of the ac susceptibility at $3.5 \mathrm{kOe}$, shown in Figure $\mathrm{S} 11$, for $\mathbf{1 b} \cdot 0.4 \mathrm{CH}_{2} \mathrm{Cl}_{2}$. On the bottom left figure, the temperature dependence of the relaxation time of $\mathbf{1 b} \cdot 0.4 \mathrm{CH}_{2} \mathrm{Cl}_{2}$ at $3.5 \mathrm{kOe}$ between 1.85 and $3.4 \mathrm{~K}$ (treatment of $\chi^{\prime} \mathrm{vs} . v$ and $\chi^{\prime \prime}$ vs. $v$ curves gives indistinguishable results; both sets of data are plotted). The solid line provides the best fit Arrhenius law to the data represented with hollow points with the reported parameter set. 


\subsection{Magnetic data for $\left[\mathrm{Cr}_{5}(\operatorname{tdpa})_{4} \mathrm{Cl}_{2}\right](2 \mathrm{a})$}

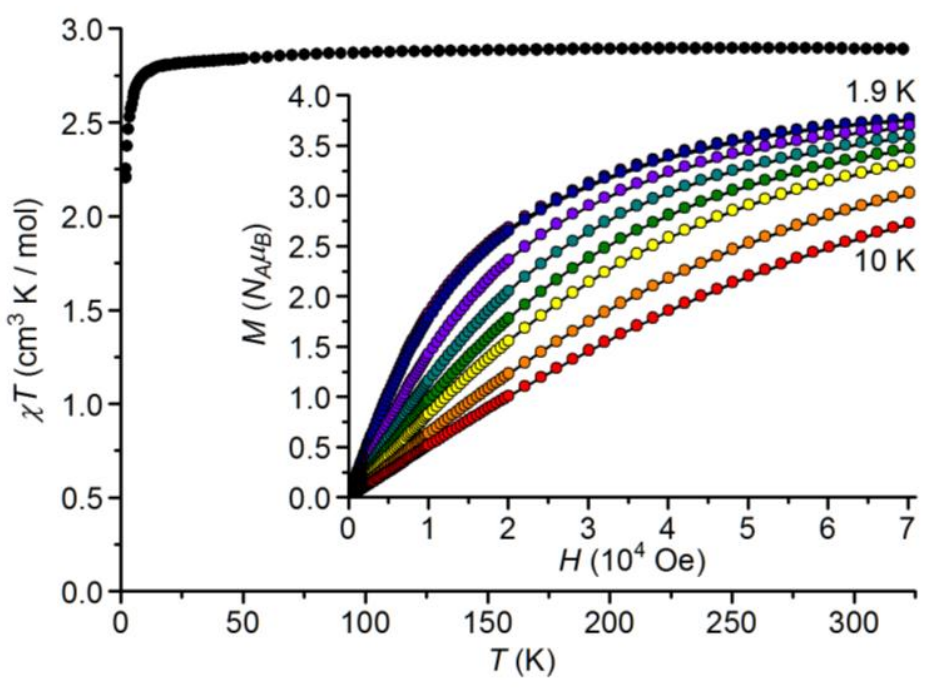

Figure S13. $\chi T$ vs. $T$ plot for $2 \mathrm{a}$ at $1 \mathrm{kOe}$ in the temperature range $1.85-320 \mathrm{~K}$. At room temperature, the $\chi T$ product is $2.89 \mathrm{~cm}^{3} \mathrm{~K} \mathrm{~mol}^{-1}$. When the temperature is lowered, the $\chi T$ product at $1 \mathrm{kOe}$ decreases reaching $2.21 \mathrm{~cm}^{3} \mathrm{~K} \mathrm{~mol}^{-1}$ at 1.85 $\mathrm{K}$. The inset presents $M$ vs. $H$ data measured at eight different temperatures (1.9, 2.0, 3.0, 4.0, 5.0, 6.0, 8.0 and 10.0 K), along with the best-fit curves to the 904 data points with the parameters reported in the text.

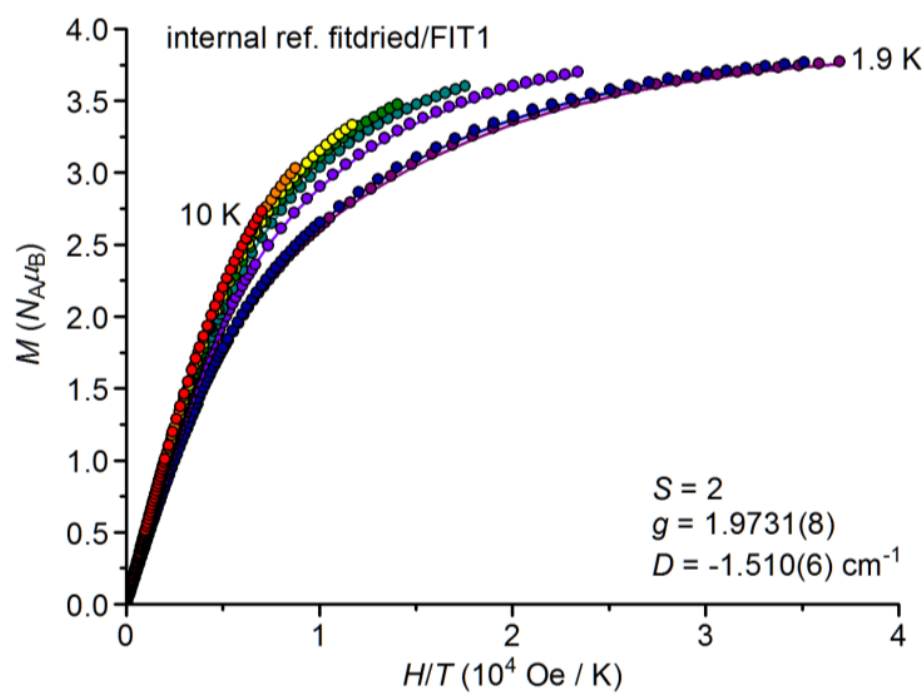

Figure S14. $M$ vs. $H / T$ plot for $\mathbf{2 a}$ at temperatures between 1.9 and $10.0 \mathrm{~K}$. The solid curves provide the best fit to the 904 data points with the reported set of parameters. 

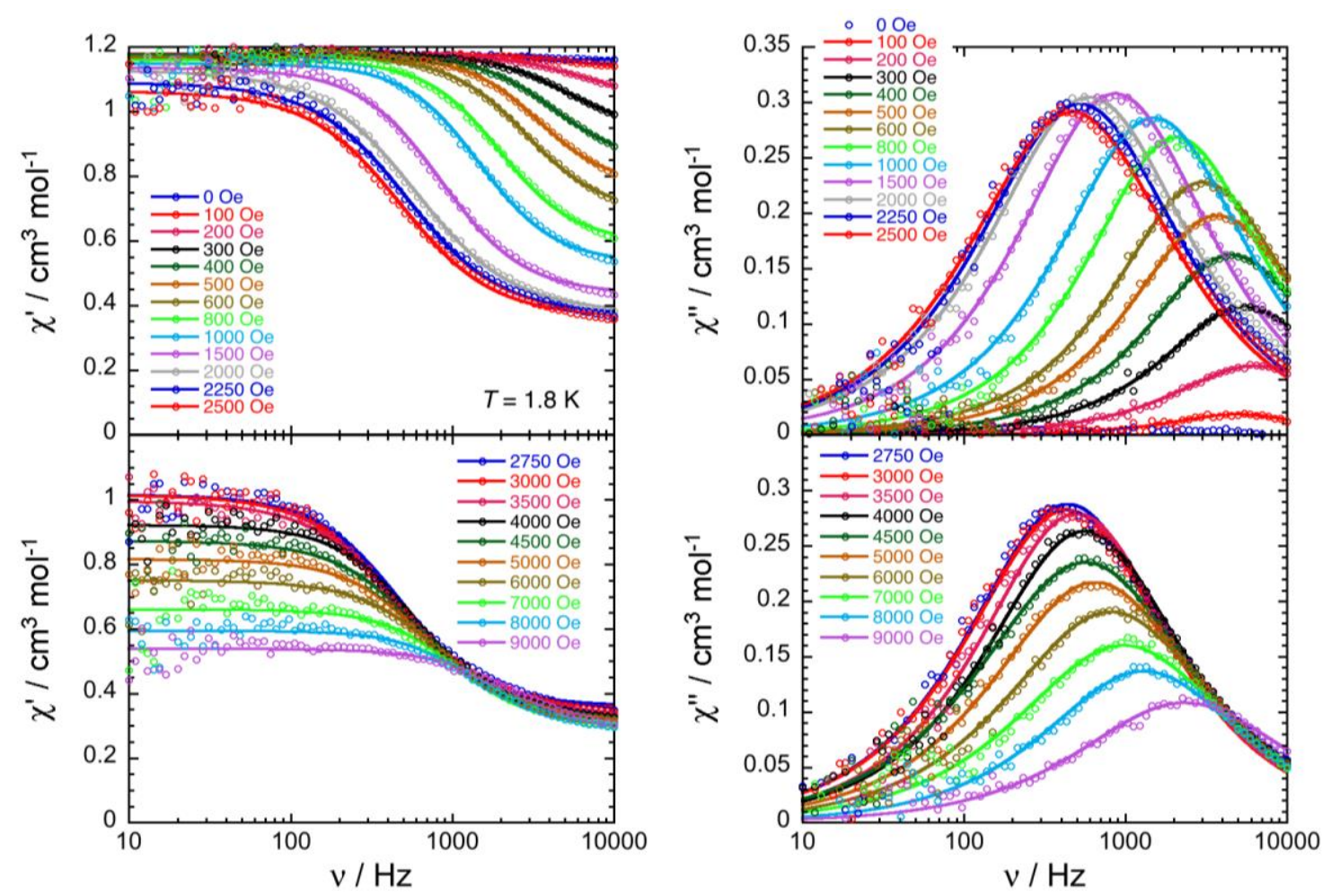

Figure S15. In-phase (left) and out-of-phase (right) components of the molar ac magnetic susceptibility of 2a measured at $1.8 \mathrm{~K}$ as a function of applied dc field between 0 and $9 \mathrm{kOe}$. The solid curves on the figures provide the best fit using the generalized Debye model.
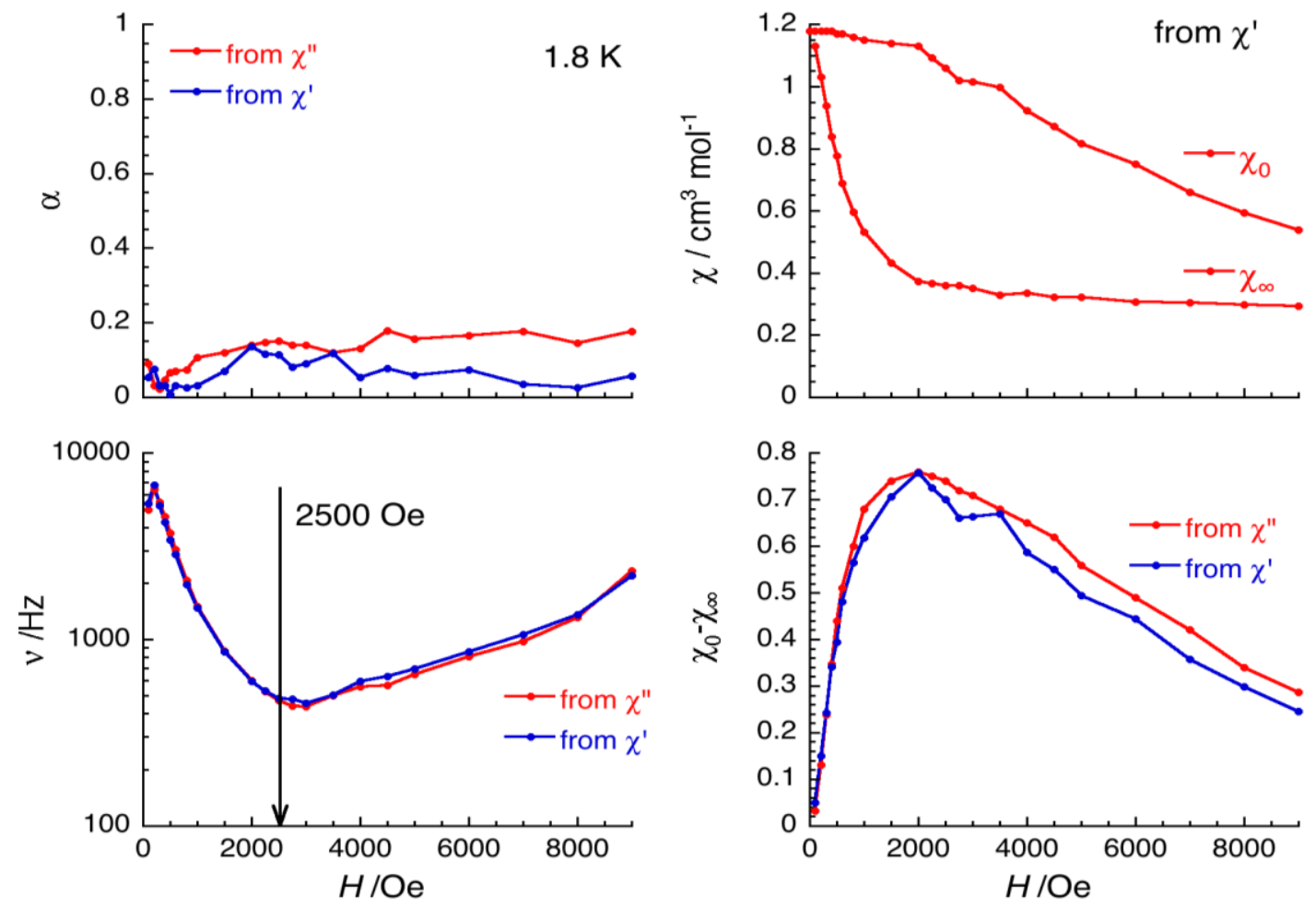

Figure S16. Field dependence of the parameters $\alpha, v, \chi_{0}, \chi_{\infty}$ and $\chi_{0}-\chi_{\infty}$ between 0 and $9 \mathrm{kOe}$ deduced from the generalized Debye fit of the frequency dependence of the real $\left(\chi^{\prime}\right)$ and imaginary $\left(\chi^{\prime \prime}\right)$ components of the ac susceptibility at $1.8 \mathrm{~K}$, shown in Figure S15, for $2 \mathbf{a}$. The slowest relaxation occurs at $2.5 \mathrm{kOe}$. 

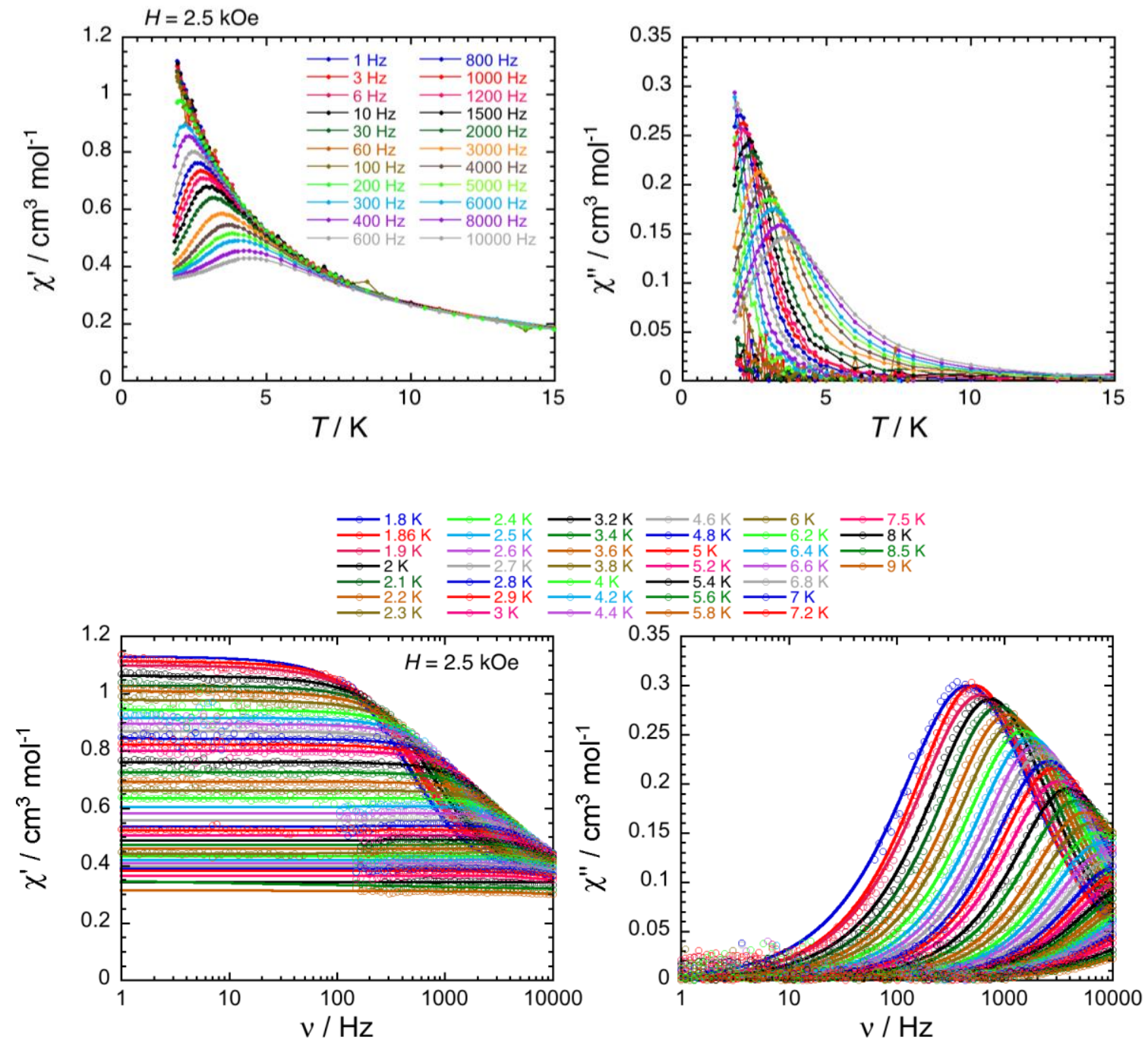

Figure S17. In-phase (left) and out-of-phase (right) components of the molar ac magnetic susceptibility of 2a measured as a function of temperature at different frequencies (top) and as a function of frequency at different temperatures (bottom) at $2.5 \mathrm{kOe}$. While solid lines on the top figures are visual guides, the solid curves on the bottom figures provide the best fit using the generalized Debye model. 

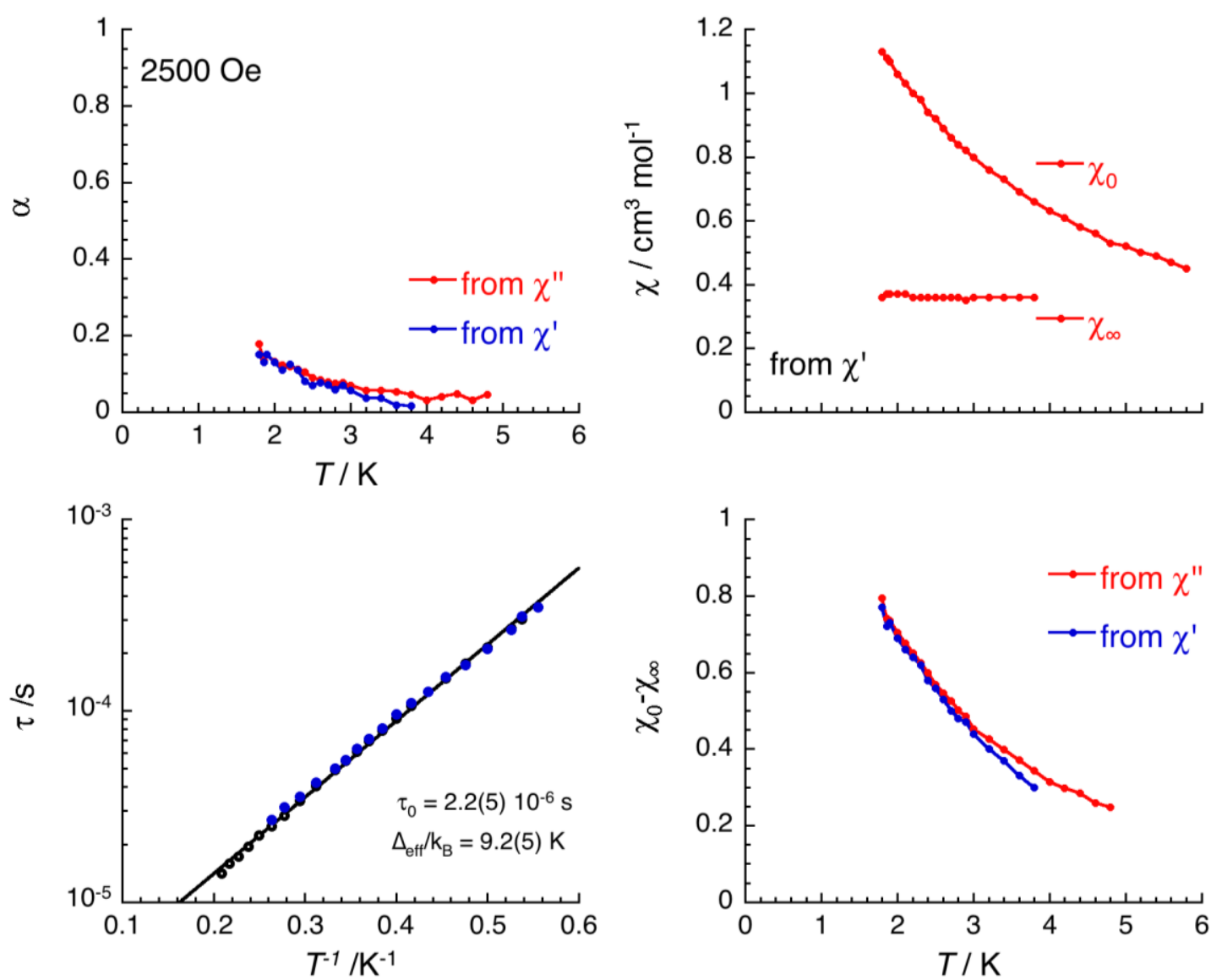

Figure S18. Temperature dependence of the parameters $\alpha, \tau, \chi_{0}, \chi_{\infty}$ and $\chi_{0}-\chi_{\infty}$ between 1.8 and $6 \mathrm{~K}$ deduced from the generalized Debye fit of the frequency dependence of the real $\left(\chi^{\prime}\right)$ and imaginary $\left(\chi^{\prime \prime}\right)$ components of the ac susceptibility at $2.5 \mathrm{kOe}$, shown in Figure S17, for 2a. On the bottom left figure, the temperature dependence of the relaxation time of 2a at $2.5 \mathrm{kOe}$ between 1.8 and $4.8 \mathrm{~K}$ (treatment of $\chi^{\prime}$ vs. $v$ and $\chi^{\prime \prime}$ vs. $v$ curves gives indistinguishable results; both sets of data are plotted). The solid line provides the best fit Arrhenius law to the data with the reported parameter set. 


\subsection{Magnetic data for $\left[\mathrm{Cr}_{5}(\mathrm{tdpa})_{4} \mathrm{Cl}_{2}\right] \cdot 4 \mathrm{CHCl}_{3} \cdot 2 \mathrm{Et}_{2} \mathrm{O}\left(2 \mathrm{a} \cdot 4 \mathrm{CHCl}_{3} \cdot 2 \mathrm{Et}_{2} \mathrm{O}\right)$}

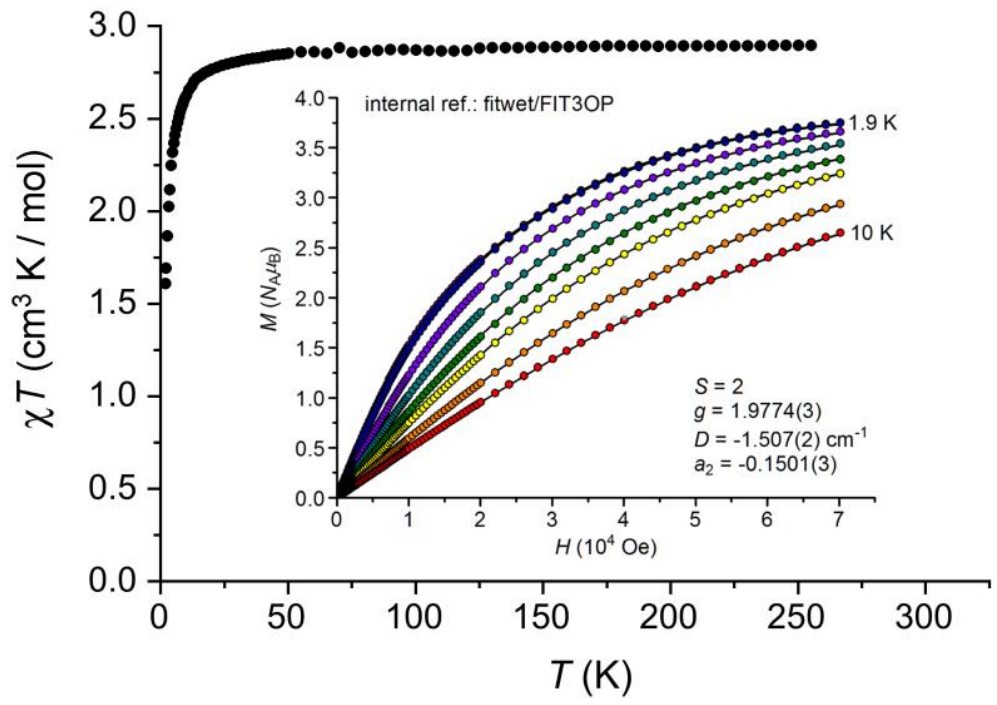

Figure S19. $\chi T$ vs. $T$ plot for $\mathbf{2 a} \cdot 4 \mathrm{CHCl}_{3} \cdot 2 \mathrm{Et}_{2} \mathrm{O}$ in the temperature range $1.86-255 \mathrm{~K}$ at $1 \mathrm{kOe}$. At the highest temperatures reached ( $255 \mathrm{~K}$ to avoid in-situ solvent loss), the $\chi T$ product is $2.89 \mathrm{~cm}^{3} \mathrm{~K} \mathrm{~mol}^{-1}$. When the temperature is lowered, the $\chi T$ product at $1 \mathrm{kOe}$ decreases reaching $1.61 \mathrm{~cm}^{3} \mathrm{~K} \mathrm{~mol}^{-1}$ at $1.86 \mathrm{~K}$. The inset presents $M$ vs. $H$ plot for $2 \mathrm{a} \cdot 4 \mathrm{CHCl}_{3} \cdot 2 \mathrm{Et}_{2} \mathrm{O}$ at eight temperature values between 1.9 and $10.0 \mathrm{~K}(1.9,2.0,3.0,4.0,5.0,6.0,8.0,10.0 \mathrm{~K})$. The solid curves provide the best fit to the 912 experimental data points with the reported set of parameters. The highest magnetization value detected is $3.75 N_{\mathrm{A}} \mu_{\mathrm{B}}$ at $1.9 \mathrm{~K}$ and $70 \mathrm{kOe}$.

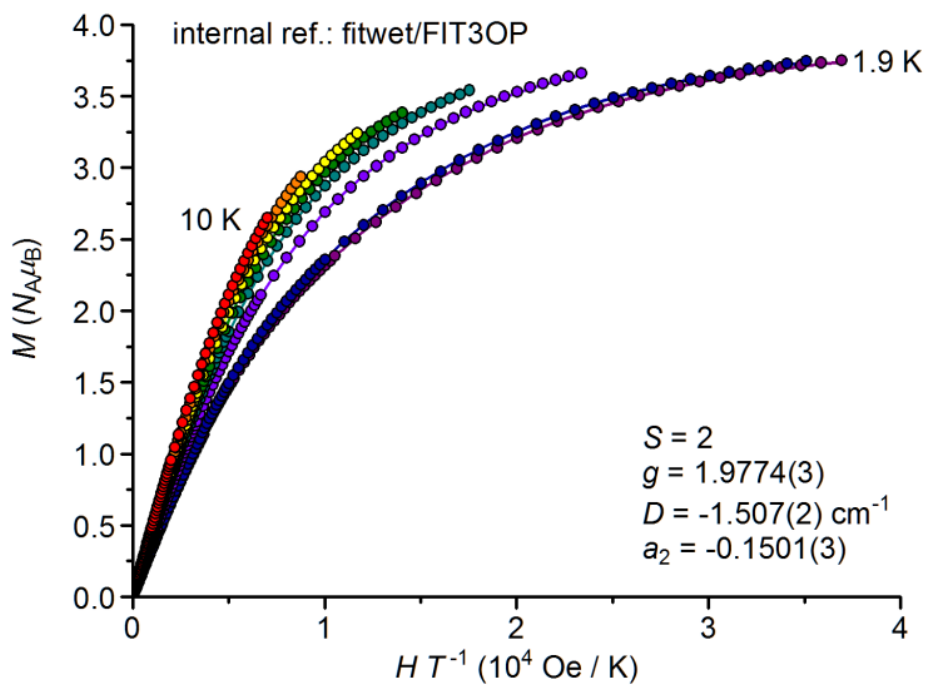

Figure S20. $M$ vs. $H / T$ plot for $2 \mathbf{a} \cdot 4 \mathrm{CHCl}_{3} \cdot 2 \mathrm{Et}_{2} \mathrm{O}$ at temperatures between 1.9 and $10.0 \mathrm{~K}(1.9,2.0,3.0,4.0,5.0,6.0,8.0$, $10.0 \mathrm{~K})$. The solid curves provide the best fit to the 912 experimental data points with the reported set of parameters. 

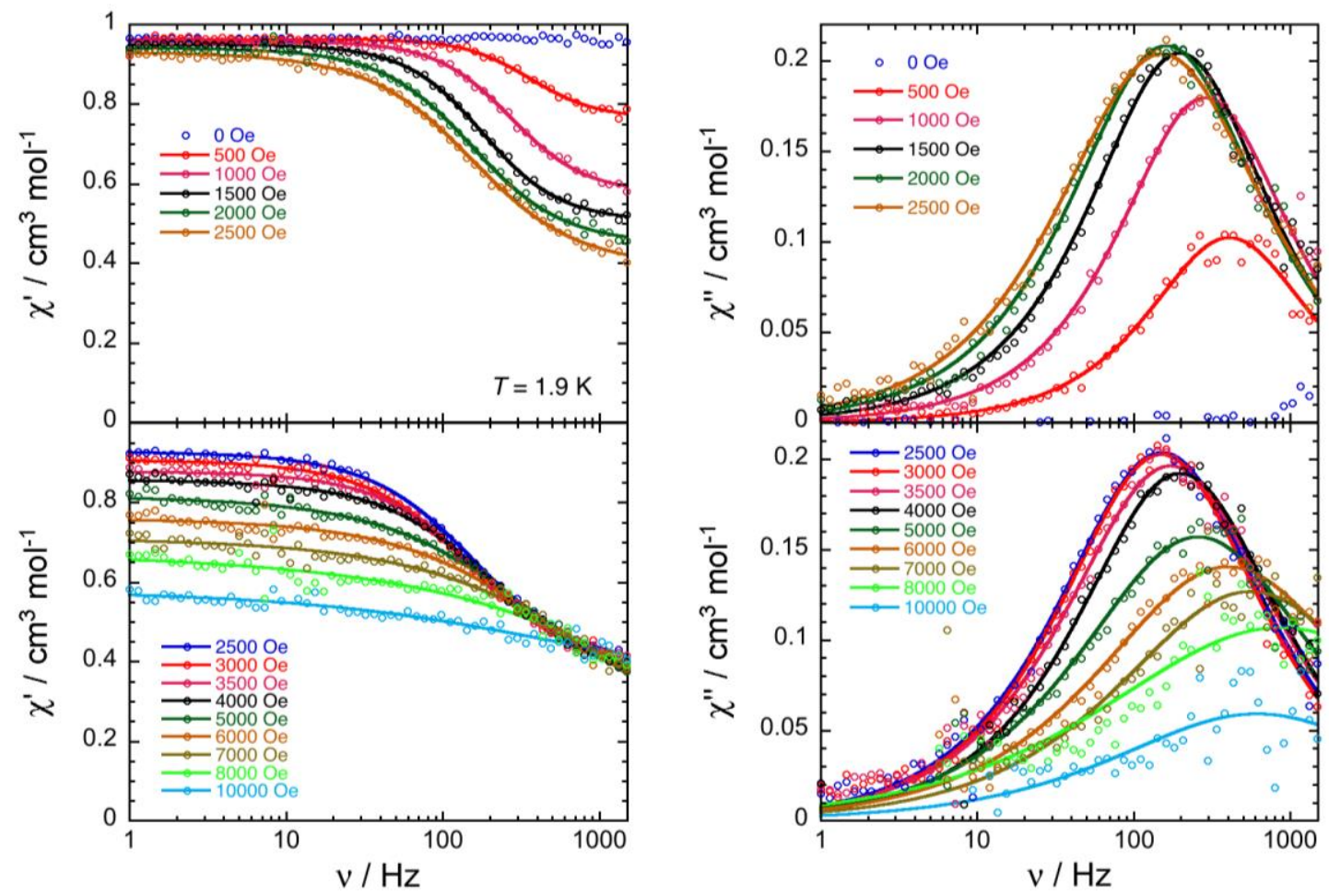

Figure S21. In-phase (left) and out-of-phase (right) components of the molar ac magnetic susceptibility of 2a. $4 \mathrm{CHCl}_{3} \cdot 2 \mathrm{Et}_{2} \mathrm{O}$ measured at $1.9 \mathrm{~K}$ as a function of applied dc field between 0 and $10 \mathrm{kOe}$. The solid curves on the figures provide the best fit using the generalized Debye model.
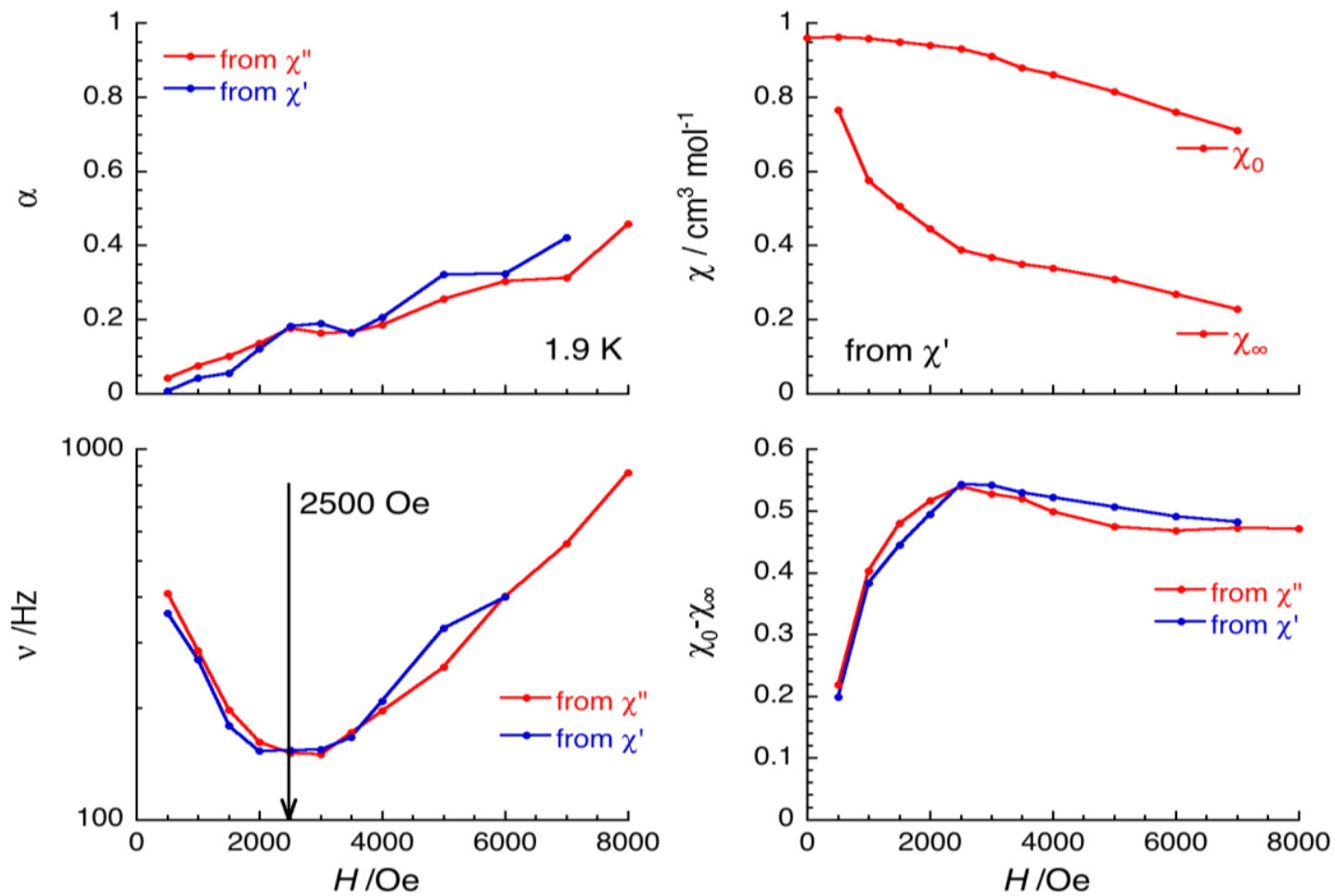

Figure S22. Field dependence of the parameters $\alpha, v, \chi_{0}, \chi_{\infty}$ and $\chi_{0}-\chi_{\infty}$ between 0 and $8 \mathrm{kOe}$ deduced from the generalized Debye fit of the frequency dependence of the real $\left(\chi^{\prime}\right)$ and imaginary $\left(\chi^{\prime \prime}\right)$ components of the ac susceptibility at $1.9 \mathrm{~K}$, shown in Figure $\mathrm{S} 21$, for $\mathbf{2 a} \cdot 4 \mathrm{CHCl}_{3} \cdot 2 \mathrm{Et}_{2} \mathrm{O}$. The slowest relaxation occurs at $2.5 \mathrm{kOe}$. 

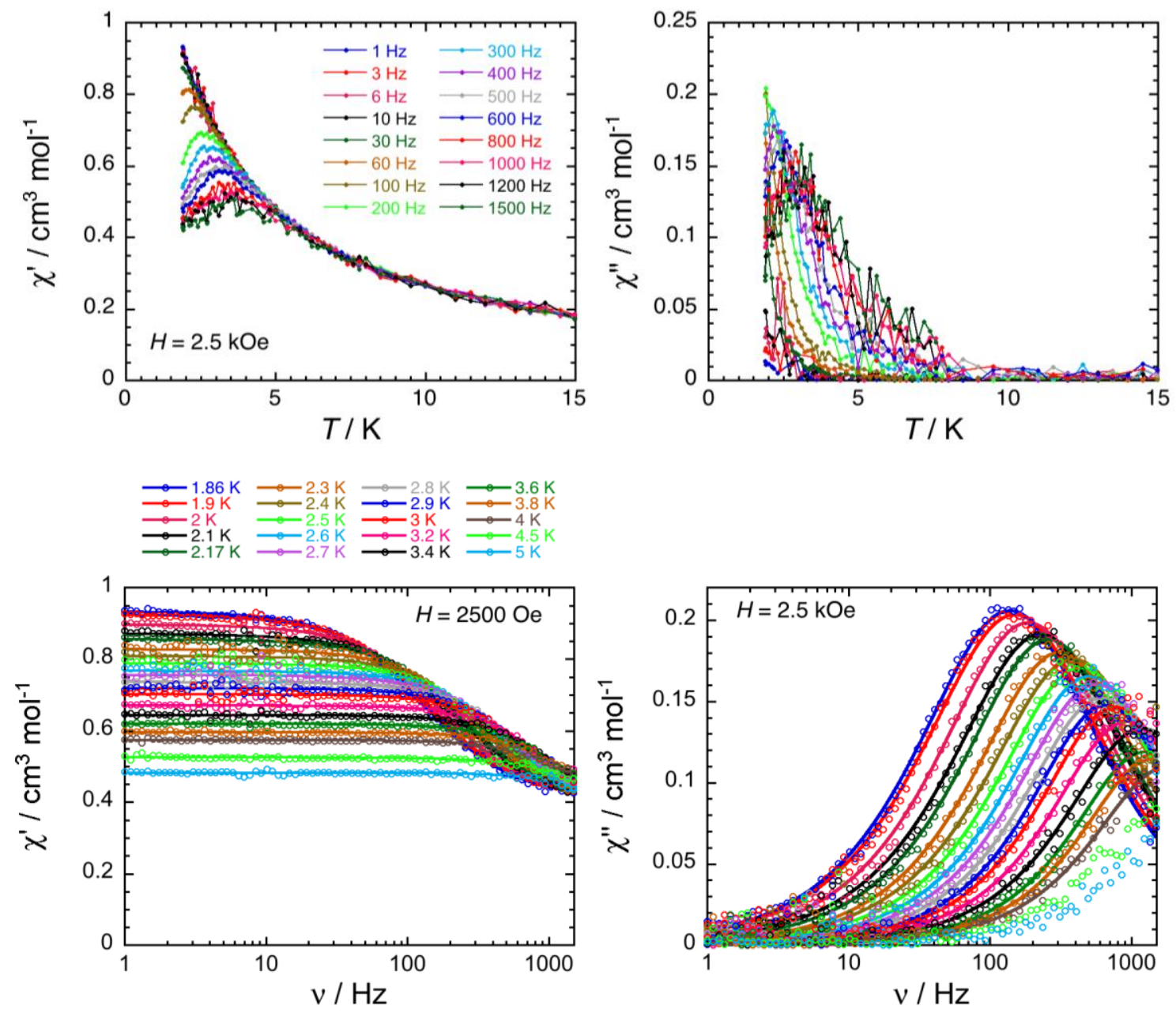

Figure S23. In-phase (left) and out-of-phase (right) components of the molar ac magnetic susceptibility of $\mathbf{2 a} \cdot 4 \mathrm{CHCl}_{3} \cdot 2 \mathrm{Et}_{2} \mathrm{O}$ measured as a function of temperature at different frequencies (top) and as a function of frequency at different temperatures (bottom) at $2.5 \mathrm{kOe}$. While solid lines on the top figures are visual guides, the solid curves on the bottom figures provide the best fit using the generalized Debye model. 

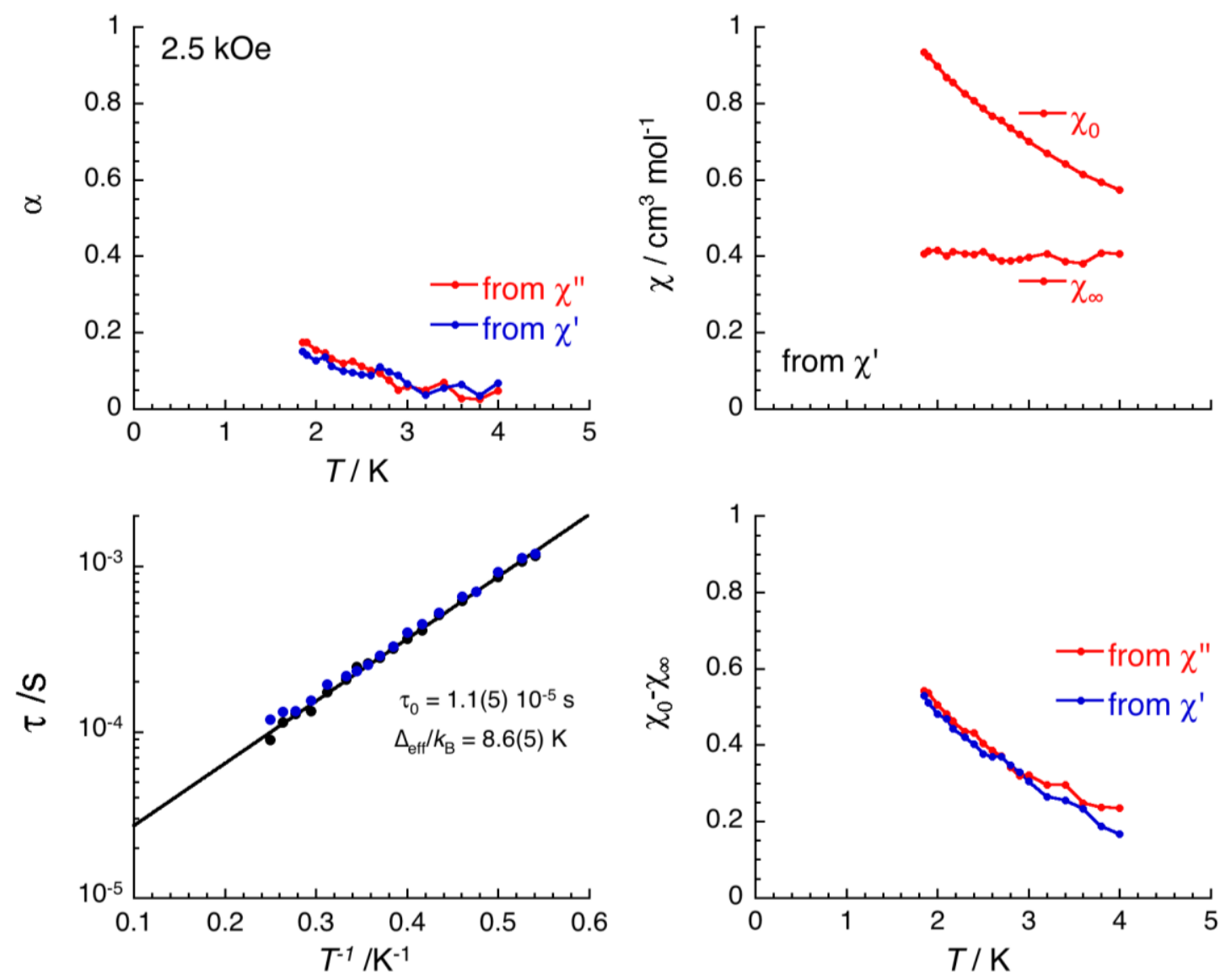

Figure S24. Temperature dependence of the parameters $\alpha, \tau, \chi_{0}, \chi_{\infty}$ and $\chi_{0}-\chi_{\infty}$ between 1.86 and $4 \mathrm{~K}$ deduced from the generalized Debye fit of the frequency dependence of the real $\left(\chi^{\prime}\right)$ and imaginary $\left(\chi^{\prime \prime}\right)$ components of the ac susceptibility at $2.5 \mathrm{kOe}$, shown in Figure $\mathrm{S} 23$, for $\mathbf{2 a} \cdot 4 \mathrm{CHCl}_{3} \cdot 2 \mathrm{Et}_{2} \mathrm{O}$. On the bottom left figure, the temperature dependence of the relaxation time of $2 \mathrm{a} \cdot 4 \mathrm{CHCl}_{3} \cdot 2 \mathrm{Et}_{2} \mathrm{O}$ at $2.5 \mathrm{kOe}$ between 1.86 and $4 \mathrm{~K}$ (treatment of $\chi^{\prime}$ vs. $v$ and $\chi^{\prime \prime}$ vs. $v$ curves gives indistinguishable results; both sets of data are plotted). The solid line provides the best fit Arrhenius law with the reported parameter set. 


\subsection{Magnetic data for $\left[\mathrm{Cr}_{5}(\mathrm{tpda})_{4}(\mathrm{NCS})_{2}\right](2 \mathrm{~b})$}

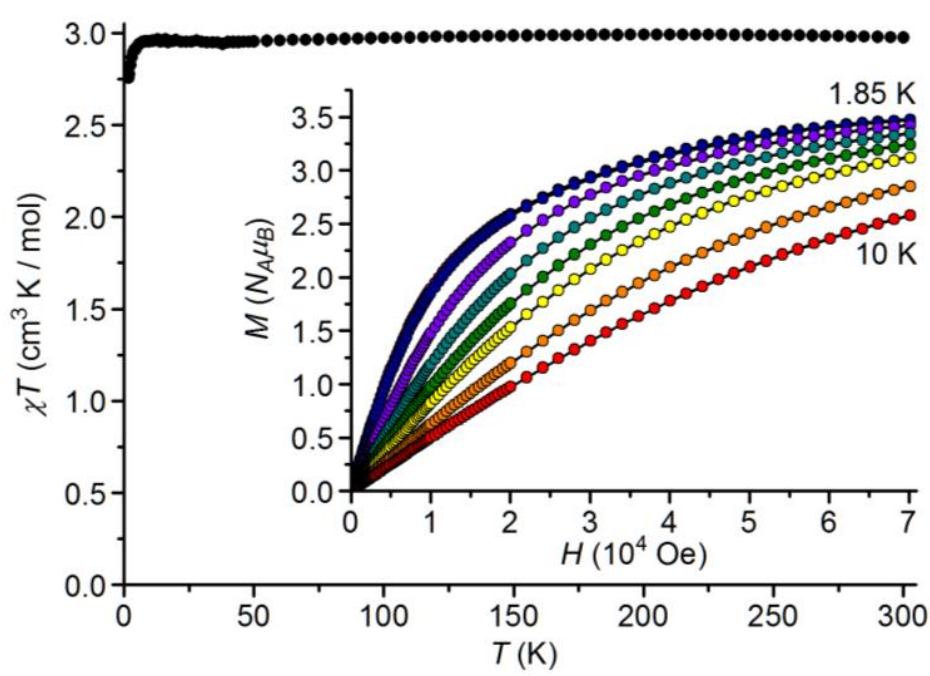

Figure S25. $\chi T$ vs. $T$ plot for $\mathbf{2 b}$ in the temperature range $1.85-300 \mathrm{~K}$ at $1 \mathrm{kOe}$. At room temperature, the $\chi T$ product is $2.96 \mathrm{~cm}^{3} \mathrm{~K} \mathrm{~mol}^{-1}$. When the temperature is lowered, the $\chi T$ product at $1 \mathrm{kOe}$ decreases reaching $2.75 \mathrm{~cm}^{3} \mathrm{~K} \mathrm{~mol}^{-1}$ at 1.85 $\mathrm{K}$. The inset presents $M$ vs. $H$ data measured at eight different temperatures (1.85, 2.0, 3.0, 4.0, 5.0, 6.0, 8.0 and 10.0 K), along with the best-fit curves to the 900 data points with the parameters reported in the text. The highest magnetization value detected is $3.47 N_{\mathrm{A}} \mu_{\mathrm{B}}$ at $1.85 \mathrm{~K}$ and $70 \mathrm{kOe}$.

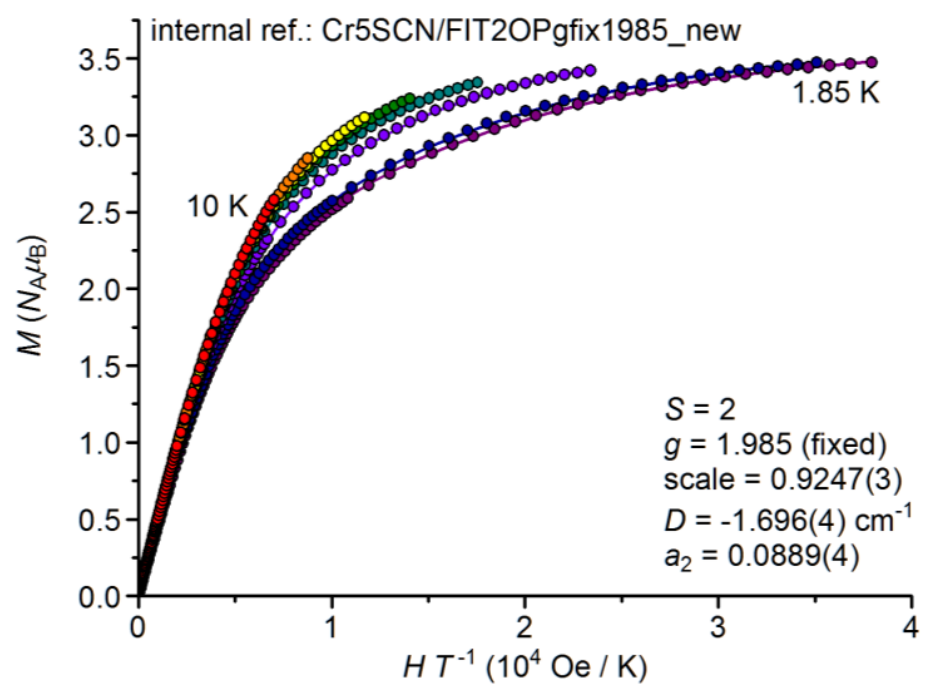

Figure S26. $M$ vs. $H / T$ plot for $\mathbf{2 b}$ at temperatures between 1.85 and $10.0 \mathrm{~K}$. The solid curves provide the best fit to the 900 data points with the reported set of parameters. 

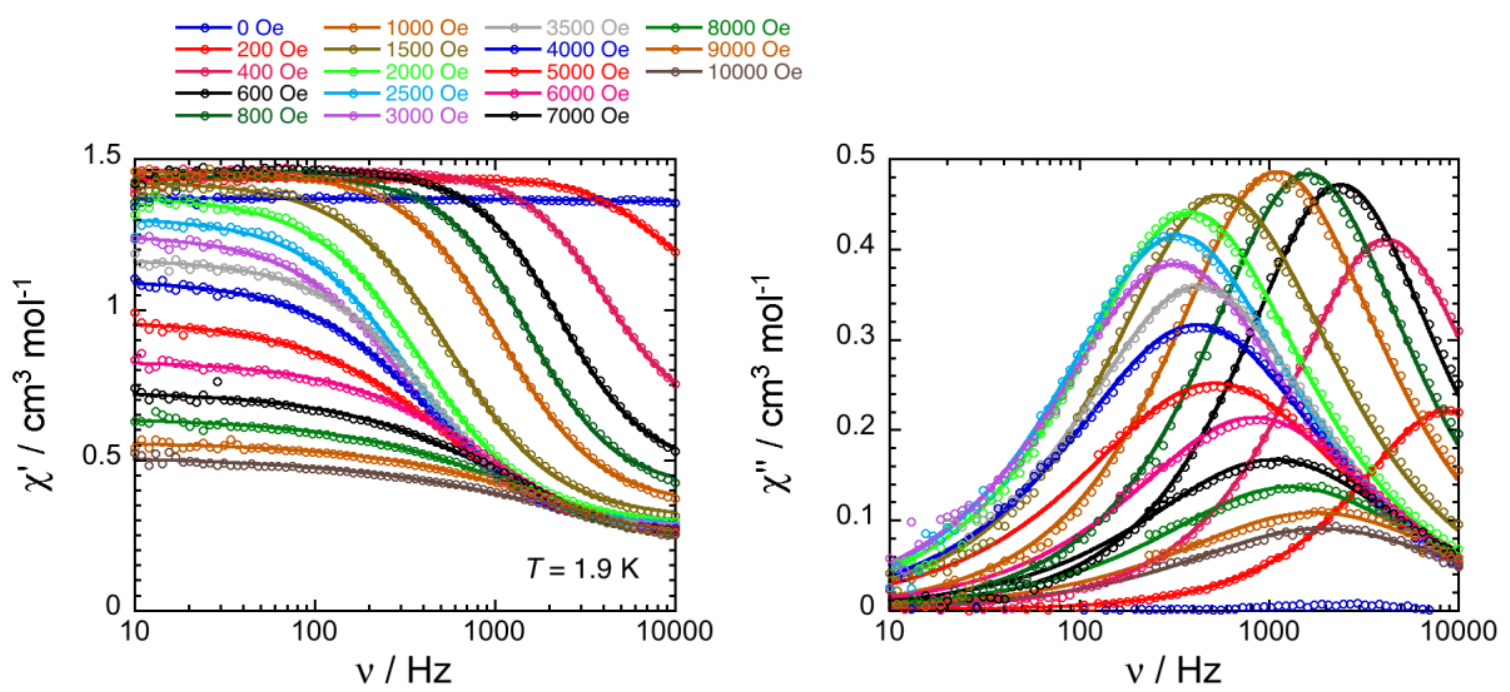

Figure S27. In-phase (left) and out-of-phase (right) components of the molar ac magnetic susceptibility of $\mathbf{2 b}$ measured at $1.9 \mathrm{~K}$ as a function of applied de field between 0 and $10 \mathrm{kOe}$. The solid curves on the figures provide the best fit using the generalized Debye model.
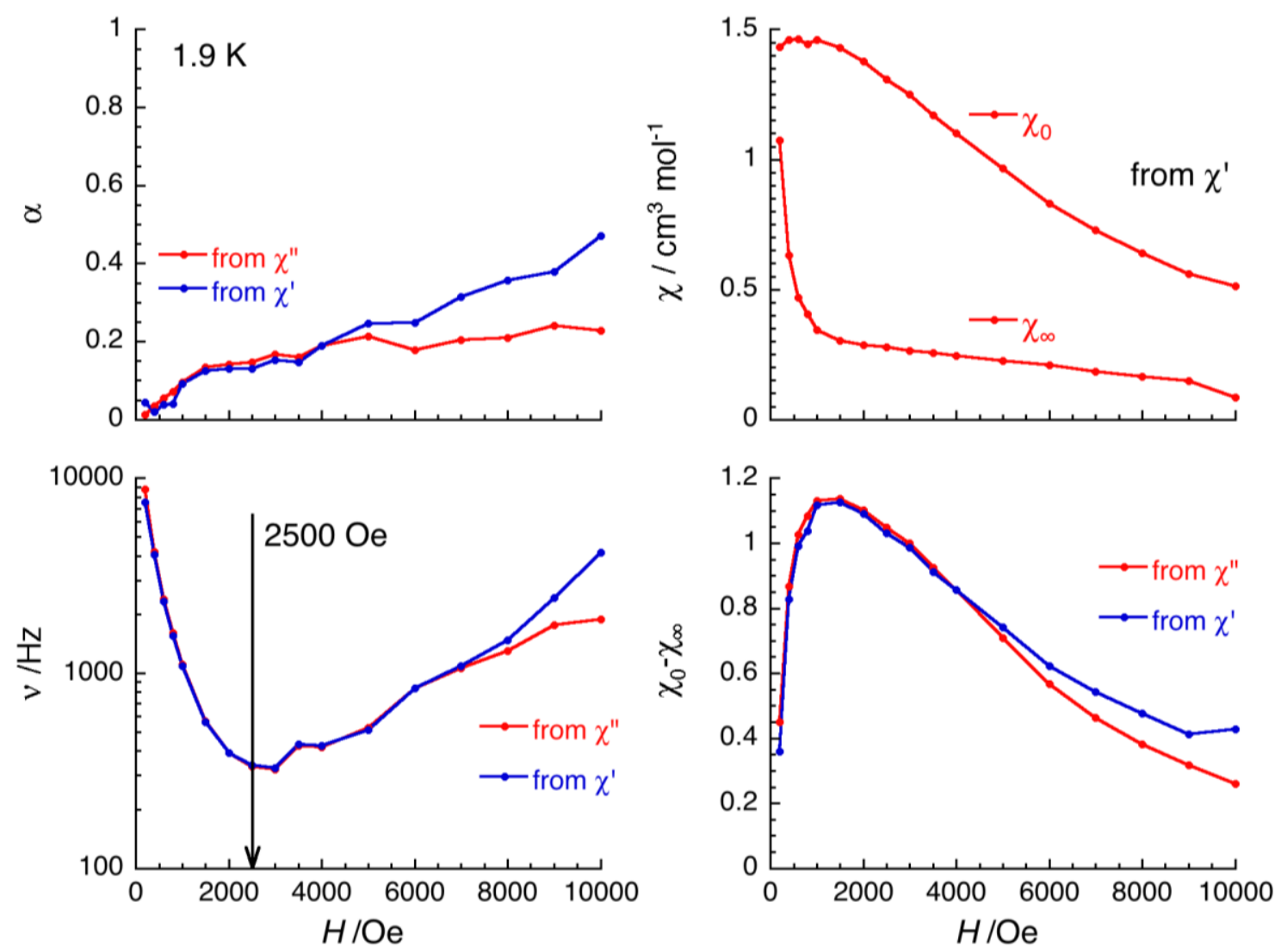

Figure S28. Field dependence of the parameters $\alpha, v, \chi_{0}, \chi_{\infty}$ and $\chi_{0}-\chi_{\infty}$ between 0 and $10 \mathrm{kOe}$ deduced from the generalized Debye fit of the frequency dependence of the real $\left(\chi^{\prime}\right)$ and imaginary $\left(\chi^{\prime \prime}\right)$ components of the ac susceptibility at $1.9 \mathrm{~K}$, shown in Figure S27, for $\mathbf{2 b}$. The slowest relaxation occurs at $2.5 \mathrm{kOe}$. 

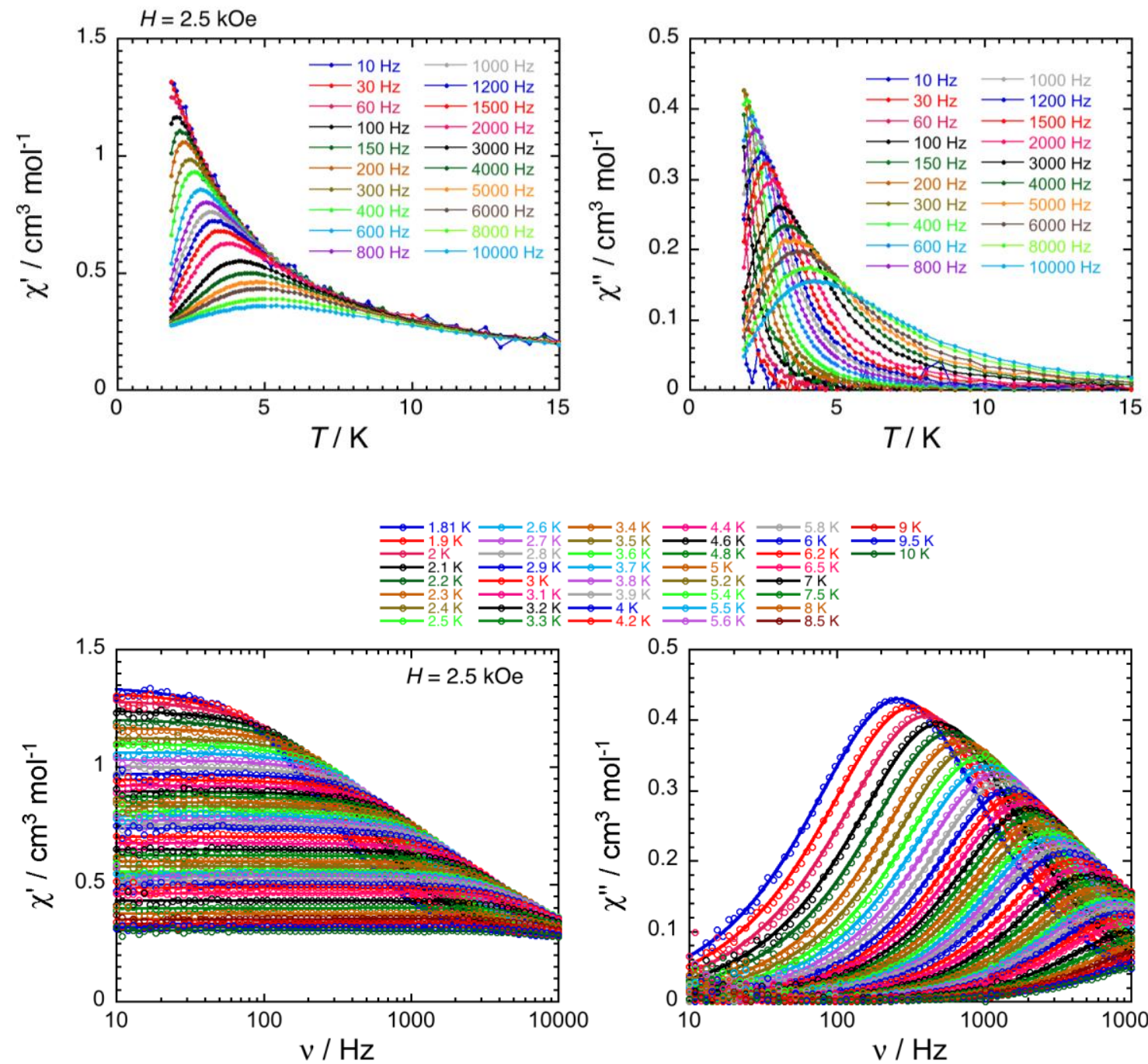

Figure S29. In-phase (left) and out-of-phase (right) components of the molar ac magnetic susceptibility of $\mathbf{2 b}$ measured as a function of temperature at different frequencies (top) and as a function of frequency at different temperatures (bottom) at $2.5 \mathrm{kOe}$. While solid lines on the top figures are visual guides, the solid curves on the bottom figures provide the best fit using the generalized Debye model. 

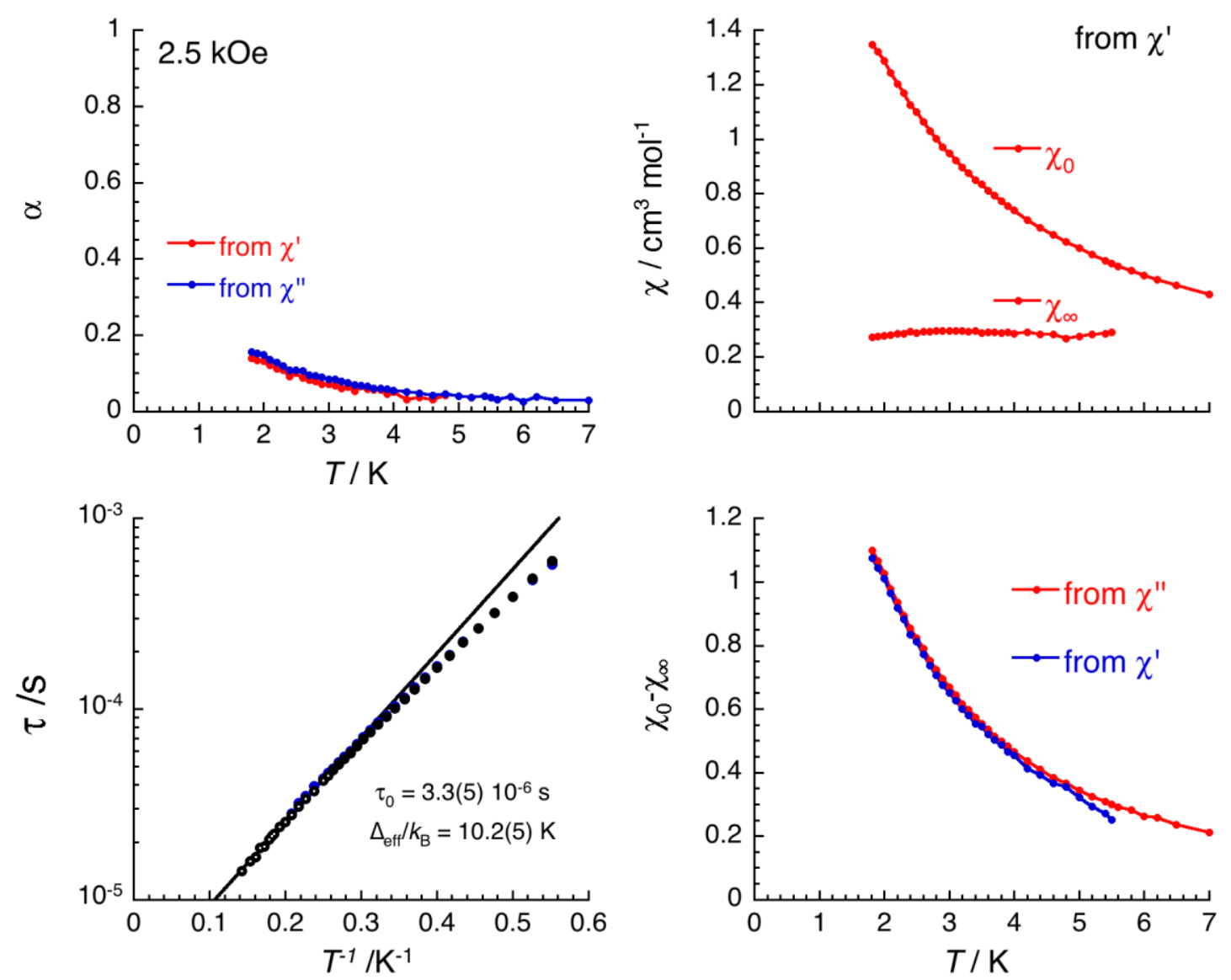

Figure S30. Temperature dependence of the parameters $\alpha, \tau, \chi_{0}, \chi_{\infty}$ and $\chi_{0}-\chi_{\infty}$ between 1.8 and $7 \mathrm{~K}$ deduced from the generalized Debye fit of the frequency dependence of the real $\left(\chi^{\prime}\right)$ and imaginary $\left(\chi^{\prime \prime}\right)$ components of the ac susceptibility at $2.5 \mathrm{kOe}$, shown in Figure S29, for $\mathbf{2 b}$. On the bottom left figure, the temperature dependence of the relaxation time of $\mathbf{2 b}$ at $2.5 \mathrm{kOe}$ between 1.8 and $7 \mathrm{~K}$ (treatment of $\chi^{\prime}$ vs. $v$ and $\chi^{\prime \prime}$ vs. $v$ curves gives indistinguishable results; both sets of data are plotted). The solid line provides the best fit Arrhenius law to the data represented with hollow points with the reported parameter set. 


\section{EPR spectroscopy}

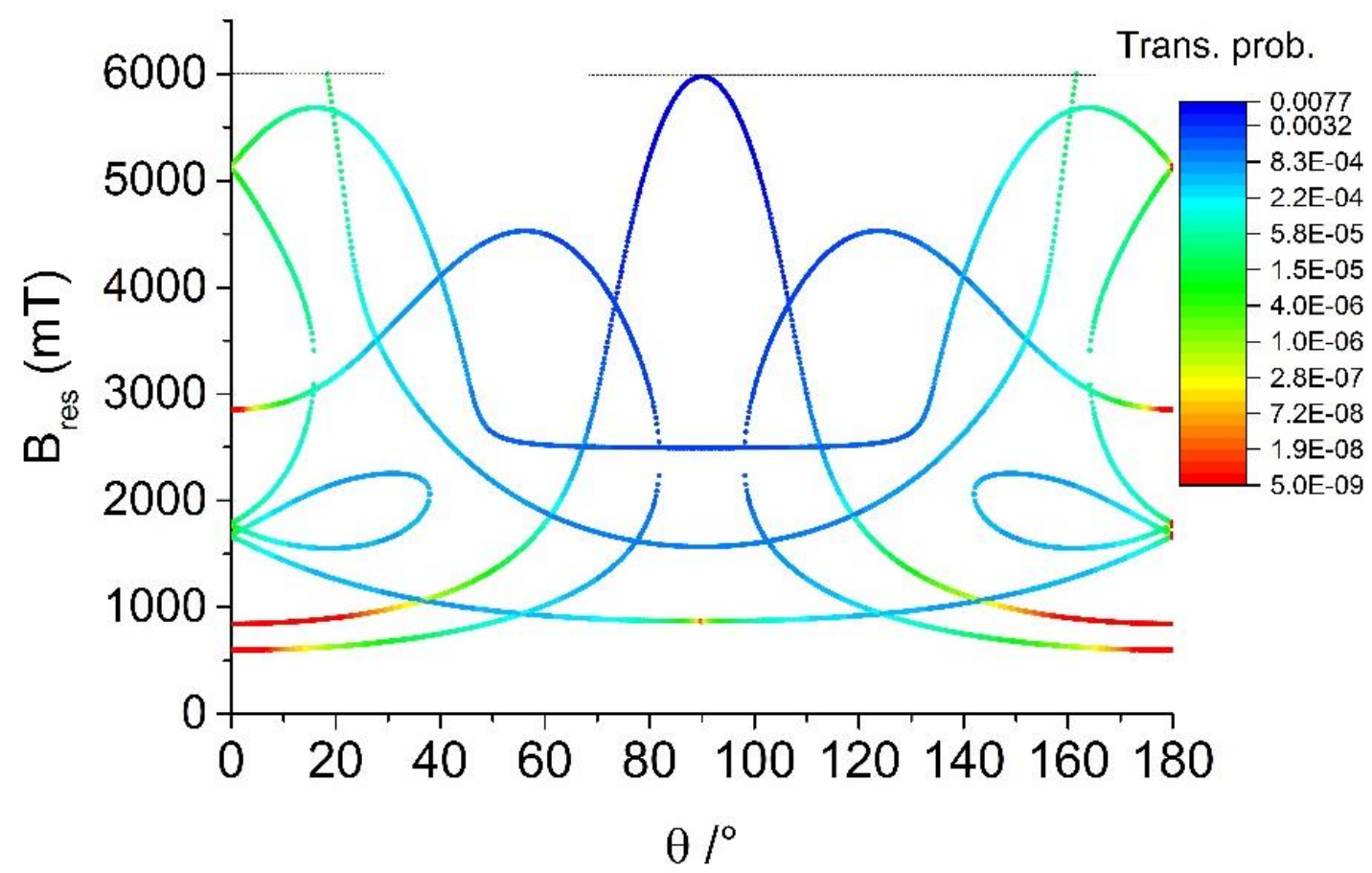

Figure S31. EPR transition roadmap as a function of polar angle $\theta$, calculated for $S=2, D=-1.6 \mathrm{~cm}^{-1}, g=1.99$ and $v=$ 94.27 GHz. Transition probabilities are weighted by relative state population at $6 \mathrm{~K}$.

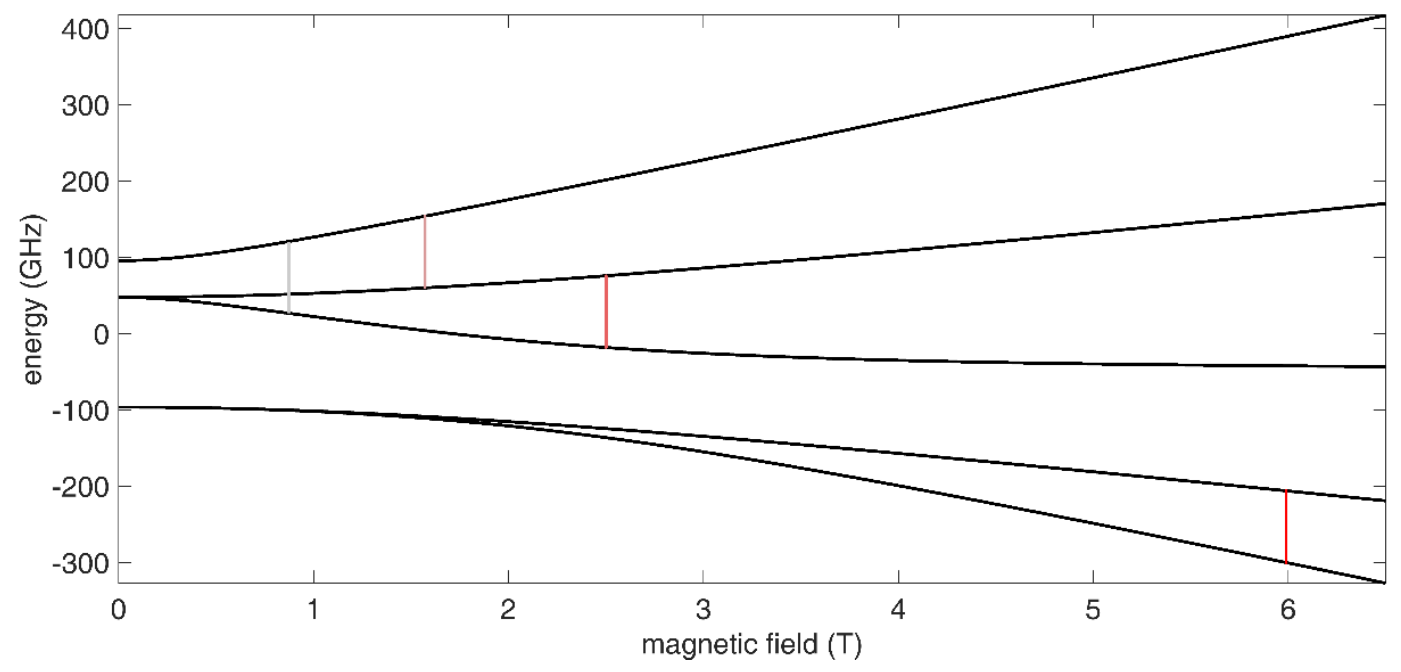

Figure S32. Spin levels calculated for $S=2, D=-1.6 \mathrm{~cm}^{-1}$ and $g=1.99$ with the magnetic field applied along the $X$ direction. Vertical bars highlight the EPR transitions expected to occur at $v=94.27 \mathrm{GHz}$. Grey-to-red color scale indicates increasing transition probability. 

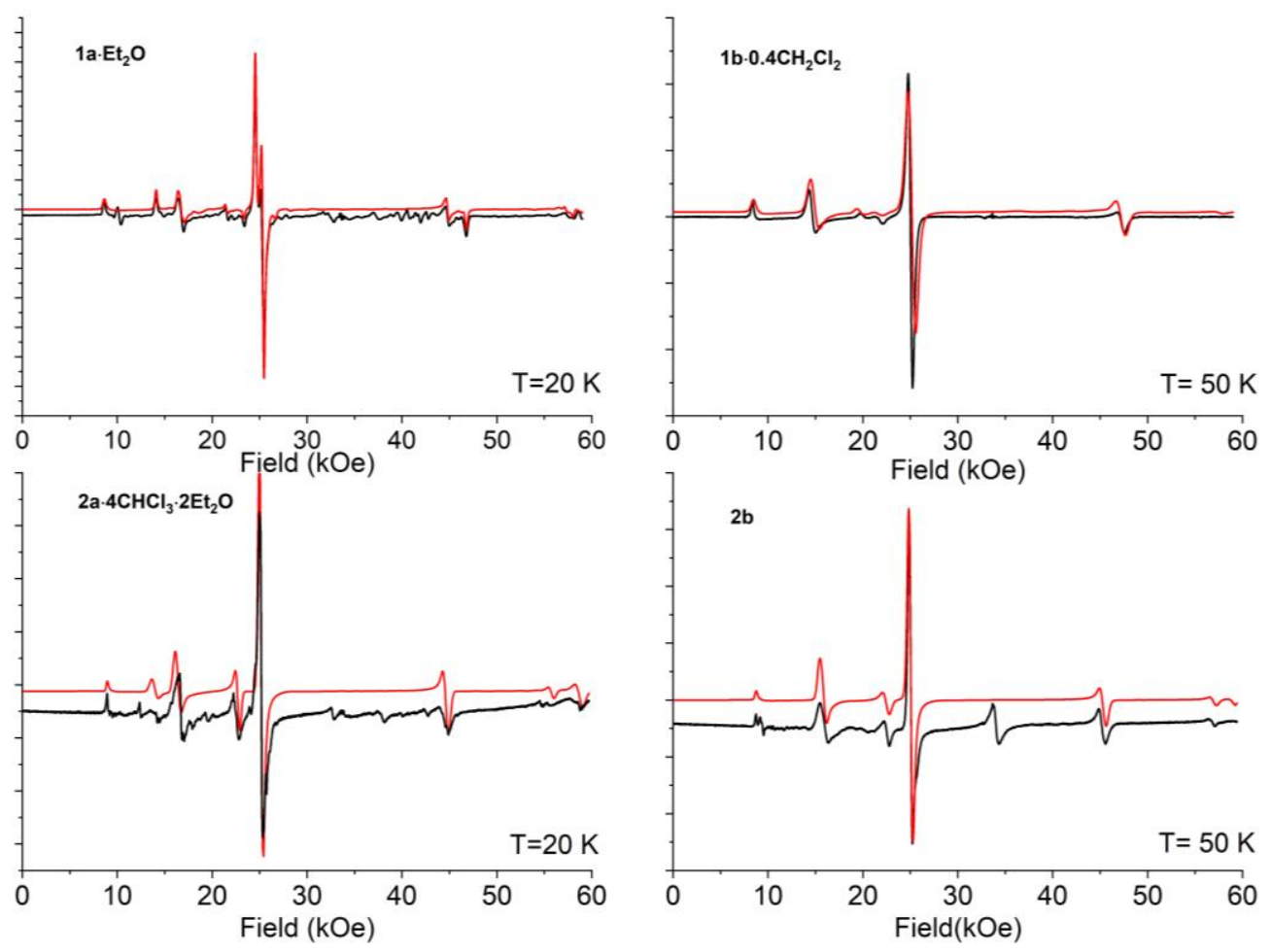

Figure S33. Experimental (black traces) and simulated (red traces) W-band ( $v=94.27 \mathrm{GHz})$ EPR spectra of polycrystalline samples of the four different compounds recorded at 20 and $50 \mathrm{~K}$.

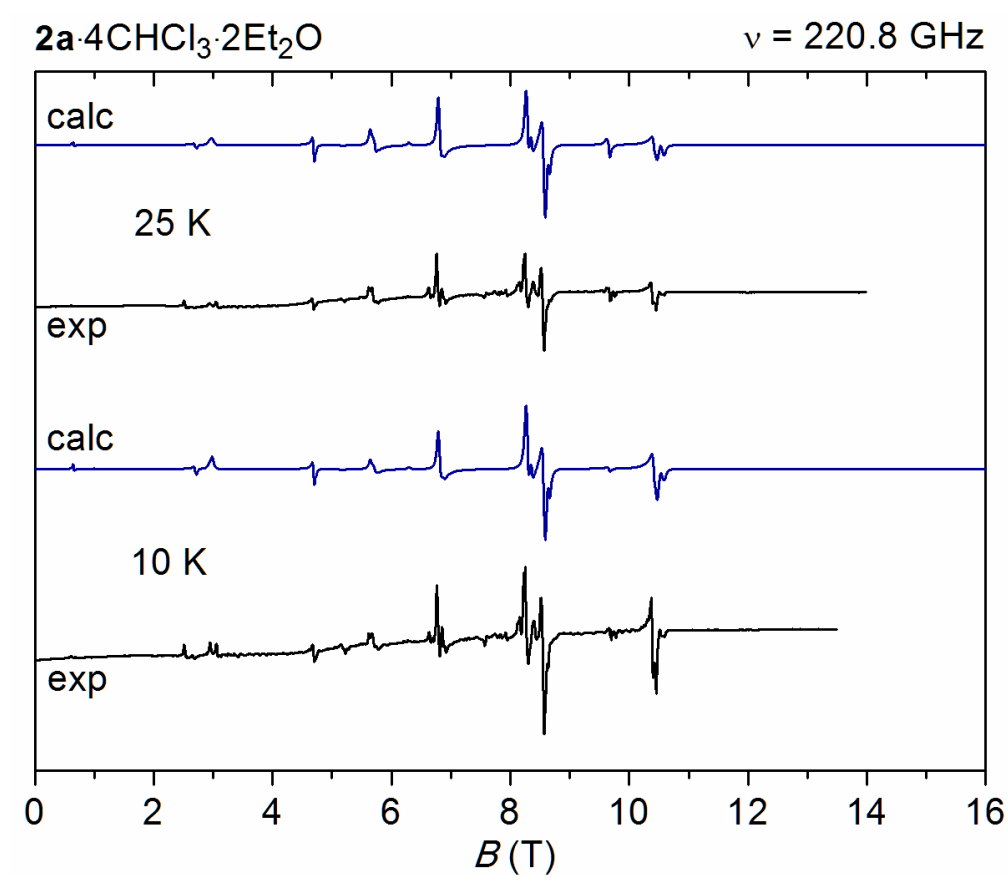

Figure S34. Experimental (black traces) and simulated (blue traces) high-frequency ( $v=220.8 \mathrm{GHz})$ EPR spectra of 2a. $4 \mathrm{CHCl}_{3} \cdot 2 \mathrm{Et}_{2} \mathrm{O}$ at 10 and $25 \mathrm{~K}$. Simulated spectra were obtained with the parameters indicated in the text, including both the major and the minor species in a 4:1 ratio. 


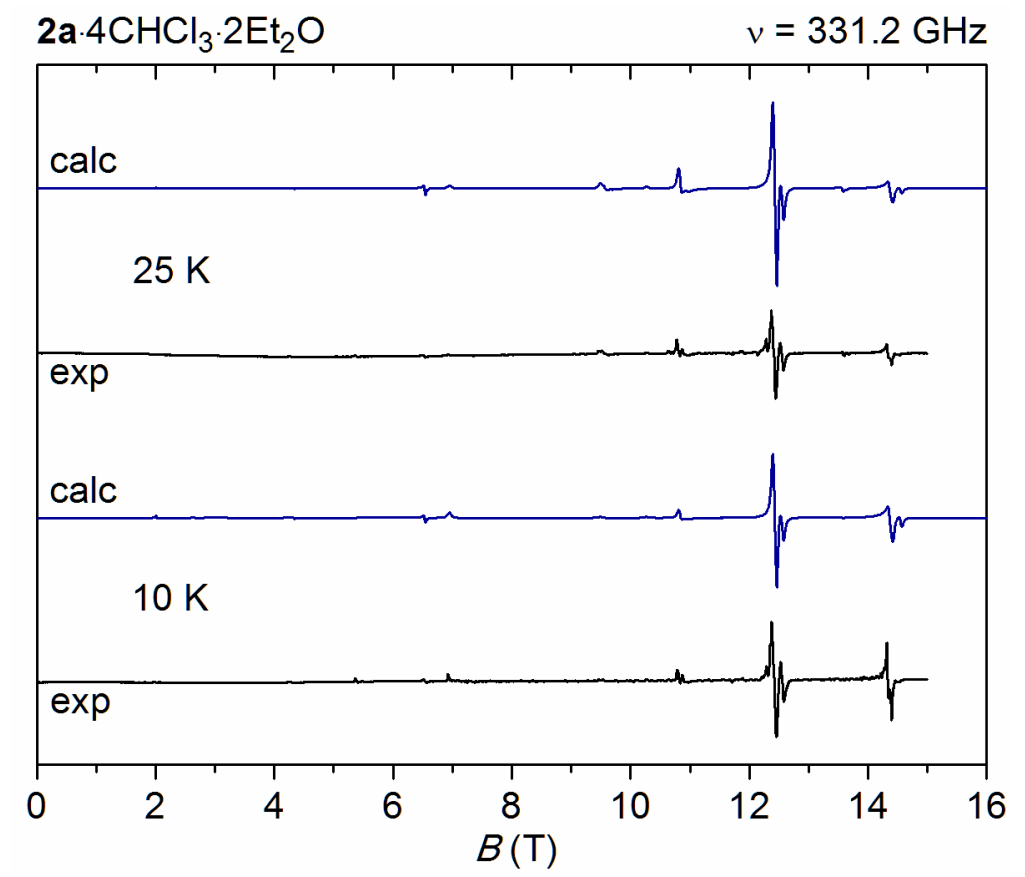

Figure S35. Experimental (black traces) and simulated (blue traces) high-frequency $(v=331.2 \mathrm{GHz}) \mathrm{EPR}$ spectra of $\mathbf{2 a} \cdot 4 \mathrm{CHCl}_{3} \cdot 2 \mathrm{Et}_{2} \mathrm{O}$ at 10 and $25 \mathrm{~K}$. Simulated spectra were obtained with the parameters indicated in the text, including both the major and the minor species in a $4: 1$ ratio.

\section{Ab initio calculations}

Evaluation of exchange-coupling constants. The Broken Symmetry (BS) DFT approach was used to calculate the nearest-neighbor and next-nearest-neighbor exchange-coupling constants in $\mathbf{1} \mathbf{a}_{\text {sym }}$. The following determinants were computed: $\mid+++>($ HS $), \mid+-+>($ BS1 $)$, and $\mid-++>($ BS2), which is degenerate with $\mid++->$ (BS3) by symmetry. The computed $\left\langle S^{2}\right\rangle$ values are 42.06, 8.38, and 8.56, respectively. The energies are: -6250.4651573 au (HS), -6250.5843150 au (BS1), -6250.546828 au (BS2 and BS3). From these values and the spin Hamiltonian $\hat{H}=J_{1}\left(\hat{\mathbf{s}}_{1} \cdot \hat{\mathbf{s}}_{2}+\hat{\mathbf{s}}_{2} \cdot \hat{\mathbf{s}}_{3}\right)+J_{2} \hat{\mathbf{s}}_{1} \cdot \hat{\mathbf{s}}_{3}$, where $\mathbf{s}_{i}$ is the spin vector localized on Cri, exchange-coupling constants are evaluated as $J_{1}=1635 \mathrm{~cm}^{-1}$ and $J_{2}=606 \mathrm{~cm}^{-1}$. 


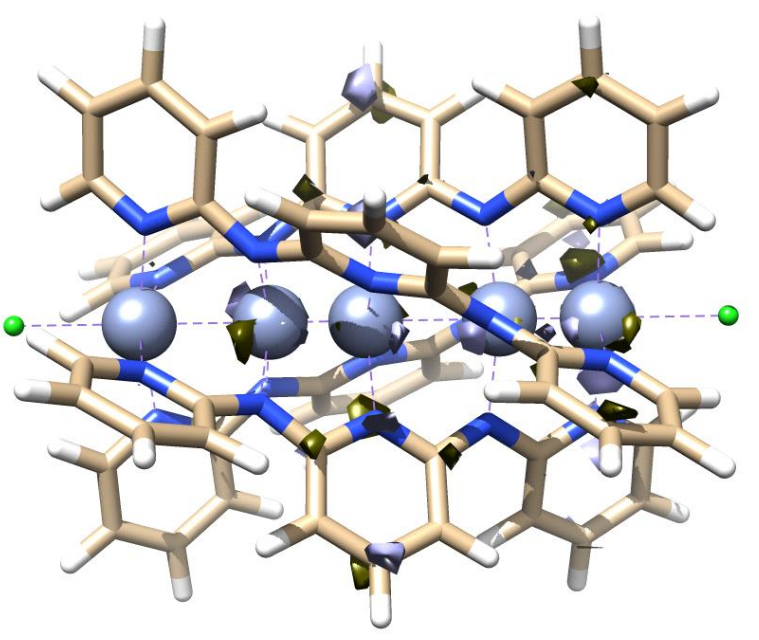

DOMO

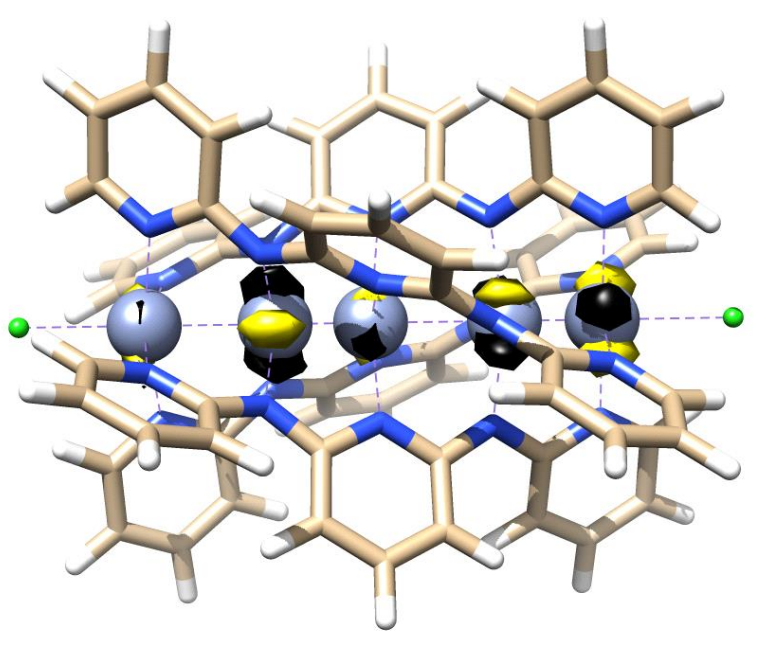

DOMO-2

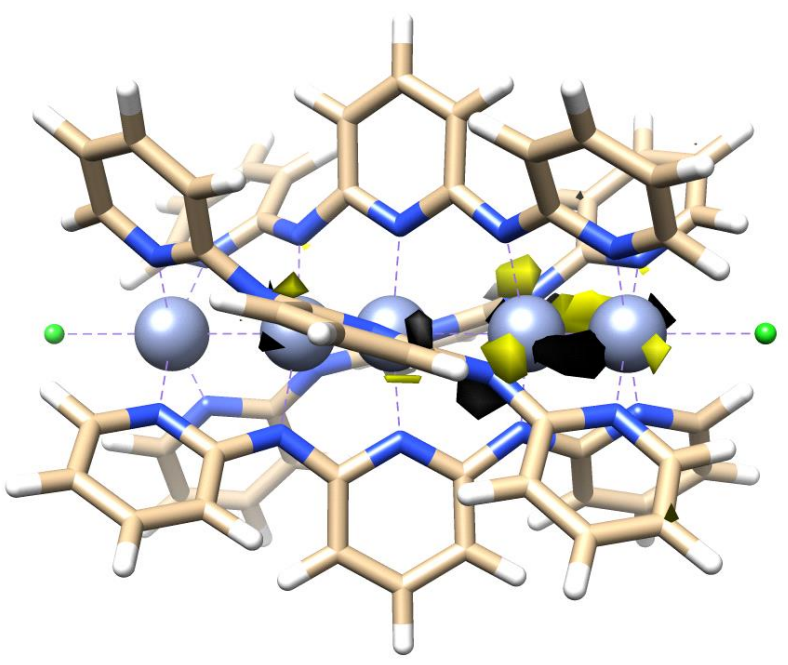

DOMO-4

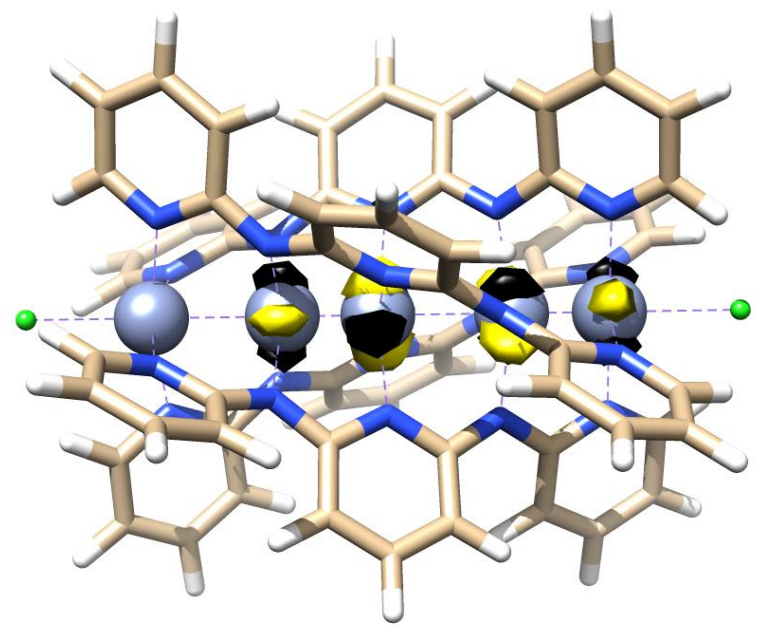

DOMO-1

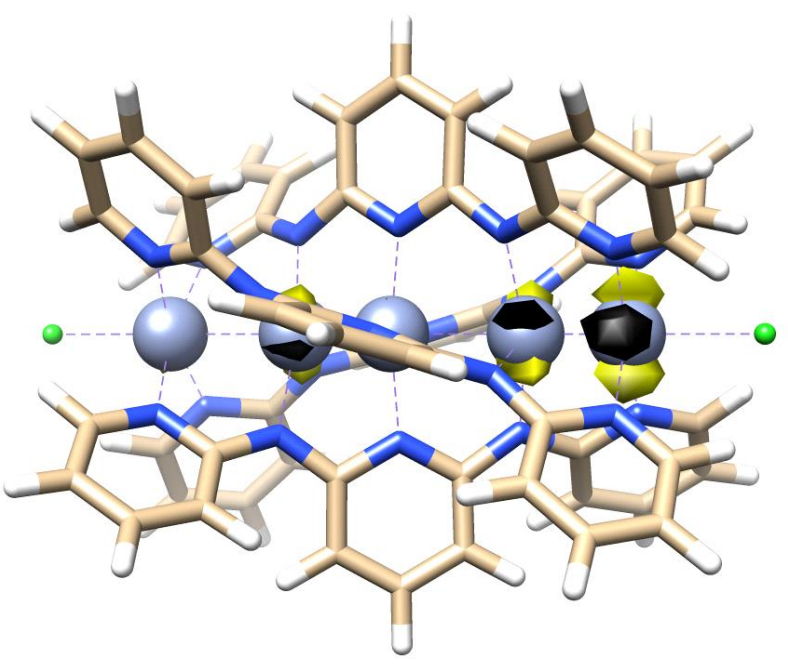

DOMO-3

Figure S36. The highest lying DOMOs in 2aunsym. Positive and negative signs of the wave function are plotted in yellow and black, respectively. 


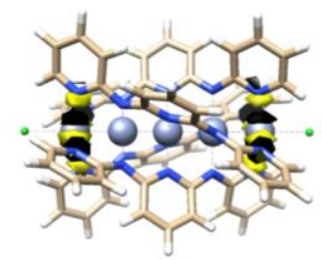

$$
\mathrm{d}_{5}{ }^{*}(\delta, \text { VIRTUAL) }
$$

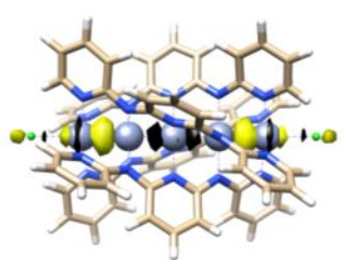

$$
\mathrm{d}_{4}^{*}(\sigma, \mathrm{SOMO})
$$
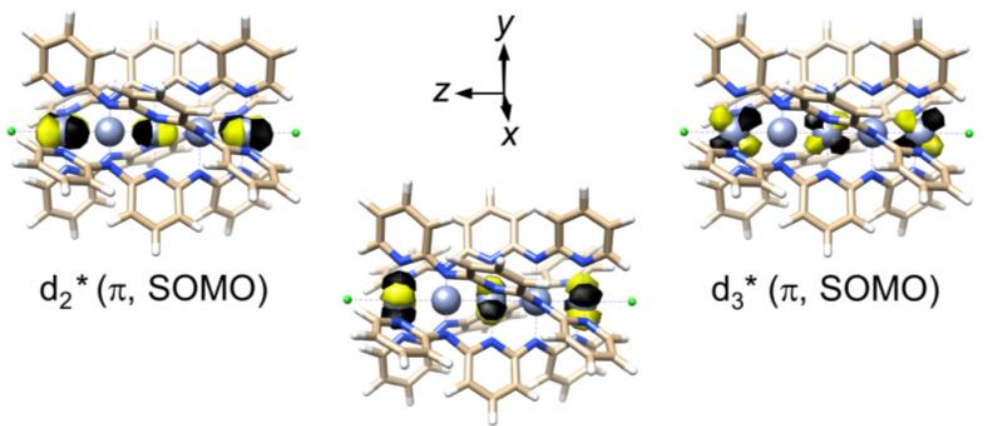

$\mathrm{d}_{1}{ }^{*}(\delta, \mathrm{SOMO})$

Figure S37. Frontier QROs in 2asym. Positive and negative signs of the wave function are plotted in yellow and black, respectively.

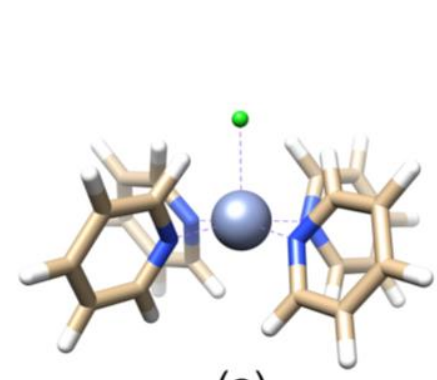

(a)

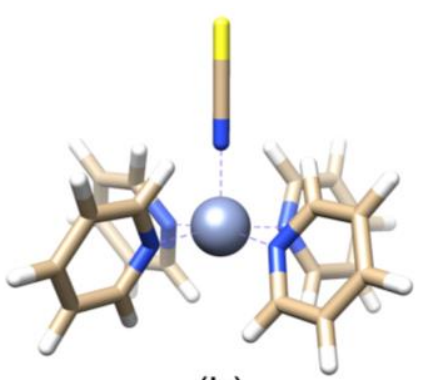

(b)

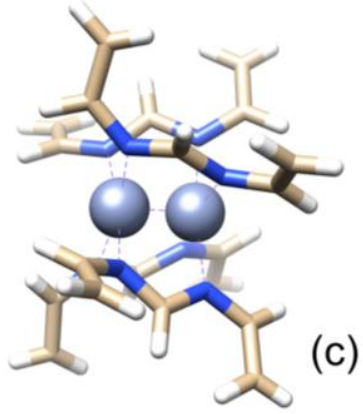

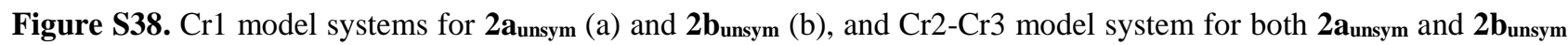
(c). The $\mathrm{Cr}^{2+}$ ions are represented as silver spheres, while brown, blue, green, yellow, and white colors are used for carbon, nitrogen, chlorine, sulfur, and hydrogen atoms, respectively. 


\section{Calculation of $D$ parameter using quasi-restricted DFT approach}

\subsection{Treatment of spin-orbit coupling}

Following initial work by Neese et al., ${ }^{14-16}$ spin-orbit (SO) coupling is here represented by the effective oneelectron operator:

$$
\begin{aligned}
& \widehat{H}_{\mathrm{SO}}=\sum_{i} \hat{\mathbf{h}}^{\mathrm{SO}}(i) \cdot \hat{\mathbf{s}}(i) \\
& \hat{h}_{k}^{\mathrm{SO}}(i)=\sum_{A} \xi\left(r_{i A}\right) \hat{l}_{k}^{A}(i)
\end{aligned}
$$

with $k=x, y, z$. In the above equations, $i$ and $A$ sum over electrons and nuclei, respectively, $\widehat{\mathbf{s}}(i)$ is the spin operator for the $i$ th electron, $\hat{\mathbf{I}}^{A}(i)$ is the orbital angular momentum operator for the $i$ th electron relative to the $A$ th nucleus, $\xi\left(r_{i A}\right)$ is a radial operator, and $r_{i A}=\left|\mathbf{r}_{i}-\mathbf{R}_{A}\right|$ is the distance between the $i$ th electron (with position vector $\mathbf{r}_{i}$ ) and the $A$ th nucleus (with position vector $\mathbf{R}_{A}$ ). For simplicity, we only include spin-orbit terms involving $A=\mathrm{Cr}^{2+}$ centers.

\subsection{Treatment of terminal $\mathrm{Cr}^{2+}$ center $(\mathrm{Cr} 1)$ in pentachromium(II) strings $2 \mathrm{a}_{\text {unsym }}$ and $2 \mathrm{~b}_{\text {unsym }}$}

For a complex featuring an isolated $\mathrm{Cr}^{2+}$ center (Cr1), Eq. (S2) affords:

$$
\hat{h}_{k}^{\mathrm{SO}}(i)=\xi\left(r_{i \mathrm{Cr} 1}\right) \hat{l}_{k}^{\mathrm{Cr} 1}(i)
$$

Taking molecular orbitals (MOs), $\Psi$, to coincide with $3 \mathrm{~d}$ metal orbitals centered on $\mathrm{Cr} 1$, the matrix elements of $\hat{h}_{k}^{\text {SO }}$ can be written as:

$$
\left\langle\Psi^{\prime}\left|\hat{h}_{k}^{\mathrm{SO}}\right| \Psi\right\rangle=\zeta_{3 d}\left\langle\Psi^{\prime}\left|\hat{l}_{k}^{\mathrm{Cr} 1}\right| \Psi\right\rangle
$$

where the radial integral $\zeta_{3 \mathrm{~d}}$ is the usual spin-orbit coupling constant for a $3 \mathrm{~d}$ electron of $\mathrm{Cr}^{2+}\left(230 \mathrm{~cm}^{-1}\right.$ for the free ion). ${ }^{17}$ The matrix elements of $\hat{l}_{k}^{\mathrm{Cr} 1}$ are available from a number of sources (e.g. Ref. ${ }^{18}$ ) and are gathered in Tables S5-S7 for convenience. Using Eq. (S4) and the spin-resolved orbital energies in Table 8, Eq. (10) of Ref. ${ }^{15}$ allows to calculate the contribution of $\alpha \rightarrow \alpha$ (SOMO-VIRTUAL) and $\alpha \rightarrow \beta$ (SOMO-SOMO) excitations to second-order magnetic anisotropy. Notice that the prefactor of $\alpha \rightarrow \beta$ (SOMO-SOMO) term is incorrect in Neese's article, as noted in two subsequent papers. ${ }^{19,20}$ The contributions of these excitations to the diagonal components of the zero-field splitting tensor $\mathbf{D}$ and to the $D$ parameter for the $S=2$ state (in units

of $\zeta_{3 \mathrm{~d}}^{2}$ ) are given by Eqs. (S5a-d) and Eqs. (S6a-d). In these equations as well as in Tables S5-S7, the Cr1 superscript has been dropped for simplicity, but all orbital angular momentum components are relative to $\mathrm{Cr} 1$, and all $3 \mathrm{~d}$ orbitals are centered on $\mathrm{Cr} 1$. 


$$
\begin{aligned}
& D_{\alpha \rightarrow \alpha}(z z)=-\frac{1}{4 S^{2}} \frac{\left|\left\langle\mathrm{d}_{x^{2}-y^{2}}\left|\hat{l}_{z}\right| \mathrm{d}_{x y}\right\rangle\right|^{2}}{\varepsilon^{\alpha}\left(\mathrm{d}_{x^{2}-y^{2}}\right)-\varepsilon^{\alpha}\left(\mathrm{d}_{x y}\right)}=-\frac{1}{4 S^{2}} \frac{4}{\varepsilon^{\alpha}\left(\mathrm{d}_{x^{2}-y^{2}}\right)-\varepsilon^{\alpha}\left(\mathrm{d}_{x y}\right)} \\
& D_{\alpha \rightarrow \alpha}(x x)=-\frac{1}{4 S^{2}} \frac{\left|\left\langle\mathrm{d}_{x^{2}-y^{2}}\left|\hat{l}_{x}\right| \mathrm{d}_{y z}\right\rangle\right|^{2}}{\varepsilon^{\alpha}\left(\mathrm{d}_{x^{2}-y^{2}}\right)-\varepsilon^{\alpha}\left(\mathrm{d}_{y z}\right)}=-\frac{1}{4 S^{2}} \frac{1}{\varepsilon^{\alpha}\left(\mathrm{d}_{x^{2}-y^{2}}\right)-\varepsilon^{\alpha}\left(\mathrm{d}_{y z}\right)} \\
& D_{\alpha \rightarrow \alpha}(y y)=-\frac{1}{4 S^{2}} \frac{\left|\left\langle\mathrm{d}_{x^{2}-y^{2}}\left|\hat{l}_{y}\right| \mathrm{d}_{x z}\right\rangle\right|^{2}}{\varepsilon^{\alpha}\left(\mathrm{d}_{x^{2}-y^{2}}\right)-\varepsilon^{\alpha}\left(\mathrm{d}_{x z}\right)}=-\frac{1}{4 S^{2}} \frac{1}{\varepsilon^{\alpha}\left(\mathrm{d}_{x^{2}-y^{2}}\right)-\varepsilon^{\alpha}\left(\mathrm{d}_{x z}\right)} \\
& D_{\alpha \rightarrow \alpha}=D_{\alpha \rightarrow \alpha}(z z)-\frac{1}{2}\left[D_{\alpha \rightarrow \alpha}(x x)+D_{\alpha \rightarrow \alpha}(y y)\right]
\end{aligned}
$$

$$
\begin{aligned}
& D_{\alpha \rightarrow \beta}(z z)=\frac{1}{2 S(2 S-1)}\left\{\frac{\left|\left\langle\mathrm{d}_{y z}\left|\hat{l}_{z}\right| \mathrm{d}_{x z}\right\rangle\right|^{2}}{\varepsilon^{\beta}\left(\mathrm{d}_{y z}\right)-\varepsilon^{\alpha}\left(\mathrm{d}_{x z}\right)}+\frac{\left|\left\langle\mathrm{d}_{x z}\left|\hat{l}_{z}\right| \mathrm{d}_{y z}\right\rangle\right|^{2}}{\varepsilon^{\beta}\left(\mathrm{d}_{x z}\right)-\varepsilon^{\alpha}\left(\mathrm{d}_{y z}\right)}\right\}= \\
& =\frac{1}{2 S(2 S-1)}\left\{\frac{1}{\varepsilon^{\beta}\left(\mathrm{d}_{y z}\right)-\varepsilon^{\alpha}\left(\mathrm{d}_{x z}\right)}+\frac{1}{\varepsilon^{\beta}\left(\mathrm{d}_{x z}\right)-\varepsilon^{\alpha}\left(\mathrm{d}_{y z}\right)}\right\} \\
& D_{\alpha \rightarrow \beta}(x x)=\frac{1}{2 S(2 S-1)}\left\{\frac{\left|\left\langle\mathrm{d}_{x z}\left|\hat{l}_{x}\right| \mathrm{d}_{x y}\right\rangle\right|^{2}}{\varepsilon^{\beta}\left(\mathrm{d}_{x z}\right)-\varepsilon^{\alpha}\left(\mathrm{d}_{x y}\right)}+\frac{\left|\left\langle\mathrm{d}_{x y}\left|\hat{l}_{x}\right| \mathrm{d}_{x z}\right\rangle\right|^{2}}{\varepsilon^{\beta}\left(\mathrm{d}_{x y}\right)-\varepsilon^{\alpha}\left(\mathrm{d}_{x z}\right)}+\frac{\left|\left\langle\mathrm{d}_{z^{2}}\left|\hat{l}_{x}\right| \mathrm{d}_{y z}\right\rangle\right|^{2}}{\varepsilon^{\beta}\left(d_{z^{2}}\right)-\varepsilon^{\alpha}\left(\mathrm{d}_{y z}\right)}+\frac{\left|\left\langle\mathrm{d}_{y z}\left|\hat{l}_{x}\right| \mathrm{d}_{z^{2}}\right\rangle\right|^{2}}{\varepsilon^{\beta}\left(\mathrm{d}_{y z}\right)-\varepsilon^{\alpha}\left(\mathrm{d}_{z^{2}}\right)}\right\}= \\
& =\frac{1}{2 S(2 S-1)}\left\{\frac{1}{\varepsilon^{\beta}\left(\mathrm{d}_{x z}\right)-\varepsilon^{\alpha}\left(\mathrm{d}_{x y}\right)}+\frac{3}{\varepsilon^{\beta}\left(\mathrm{d}_{x y}\right)-\varepsilon^{\alpha}\left(\mathrm{d}_{x z}\right)}+\frac{3}{\varepsilon^{\beta}\left(\mathrm{d}_{z^{2}}\right)-\varepsilon^{\alpha}\left(\mathrm{d}_{y z}\right)}+\frac{3}{\varepsilon^{\beta}\left(\mathrm{d}_{y z}\right)-\varepsilon^{\alpha}\left(\mathrm{d}_{z^{2}}\right)}\right\} \\
& D_{\alpha \rightarrow \beta}(y y)=\frac{1}{2 S(2 S-1)}\left\{\frac{\left|\left\langle\mathrm{d}_{y z}\left|\hat{l}_{y}\right| \mathrm{d}_{x y}\right\rangle\right|^{2}}{\varepsilon^{\beta}\left(\mathrm{d}_{y z}\right)-\varepsilon^{\alpha}\left(\mathrm{d}_{x y}\right)}+\frac{\left|\left\langle\mathrm{d}_{x y}\left|\hat{l}_{y}\right| \mathrm{d}_{y z}\right\rangle\right|^{2}}{\varepsilon^{\beta}\left(\mathrm{d}_{x y}\right)-\varepsilon^{\alpha}\left(\mathrm{d}_{y z}\right)}+\frac{\left|\left\langle\mathrm{d}_{z^{2}}\left|\hat{l}_{y}\right| \mathrm{d}_{x z}\right\rangle\right|^{2}}{\varepsilon^{\beta}\left(\mathrm{d}_{z^{2}}\right)-\varepsilon^{\alpha}\left(\mathrm{d}_{x z}\right)}+\frac{\left|\left\langle\mathrm{d}_{x z}\left|\hat{l}_{y}\right| \mathrm{d}_{z^{2}}\right\rangle\right|^{2}}{\varepsilon^{\beta}\left(\mathrm{d}_{x z}\right)-\varepsilon^{\alpha}\left(\mathrm{d}_{z^{2}}\right)}\right\}= \\
& =\frac{1}{2 S(2 S-1)}\left\{\frac{1}{\varepsilon^{\beta}\left(\mathrm{d}_{y z}\right)-\varepsilon^{\alpha}\left(\mathrm{d}_{x y}\right)}+\frac{3}{\varepsilon^{\beta}\left(\mathrm{d}_{x y}\right)-\varepsilon^{\alpha}\left(\mathrm{d}_{y z}\right)}+\frac{3}{\varepsilon^{\beta}\left(\mathrm{d}_{z^{2}}\right)-\varepsilon^{\alpha}\left(\mathrm{d}_{x z}\right)}+\frac{3}{\varepsilon^{\beta}\left(\mathrm{d}_{x z}\right)-\varepsilon^{\alpha}\left(\mathrm{d}_{z^{2}}\right)}\right\} \quad(\mathrm{S} 6 \mathrm{c}) \\
& D_{\alpha \rightarrow \beta}=D_{\alpha \rightarrow \beta}(z z)-\frac{1}{2}\left[D_{\alpha \rightarrow \beta}(x x)+D_{\alpha \rightarrow \beta}(y y)\right]
\end{aligned}
$$

\subsection{Treatment of trichromium(II) strings $1 a_{\text {sym }}$ and $1 b_{\text {sym }}$}

For a trichromium(II) species, the spatial components of $\hat{\mathbf{h}}^{\mathrm{SO}}(i)$ read as:

$$
\hat{h}_{k}^{\mathrm{SO}}(i)=\xi\left(r_{i \mathrm{Cr} 1}\right) \hat{l}_{k}^{\mathrm{Cr} 1}(i)+\xi\left(r_{i \mathrm{Cr} 2}\right) \hat{l}_{k}^{\mathrm{Cr} 2}(i)+\xi\left(r_{i \mathrm{Cr} 3}\right) \hat{l}_{k}^{\mathrm{Cr} 3}(i)
$$

We introduce the further approximation that spin-orbit terms involving the $i$ th electron and the Ath nucleus are only significant when the electron occupies an orbital centered on $A$ (one-electron one-center 
approximation). ${ }^{21,22}$ As shown in the main text, the five QROs $(m=1-5)$ herein considered are non-bonding linear combinations of 3d-type orbitals centered on terminal chromium(II) ions $(A=\mathrm{Cr} 1, \mathrm{Cr} 3)$ :

$$
\mathrm{d}_{m}^{*}=2^{-1 / 2}\left[\mathrm{~d}_{\Gamma(m)}^{\mathrm{Cr} 1}+\mathrm{d}_{\Gamma^{\prime}(m)}^{\mathrm{Cr} 3}\right]
$$

where $\Gamma(m)$ and $\Gamma^{\prime}(m)$ label the particular type of real $3 \mathrm{~d}$ orbitals involved $\left(x y, x z, y z, z^{2}, x^{2}-y^{2}\right.$, or combinations thereof) expressed in a local reference frame with origin on $\mathrm{Cr} j(j=1,3)$. Since $\mathrm{Cr} 2$ does not contribute to these QROs, the second term in Eq. (S7) is irrelevant and the matrix elements between two QROs $\mathrm{d}_{m}^{*}$ and $\mathrm{d}_{n}^{*}$ are the sum of two one-center contributions:

$$
\left\langle\mathrm{d}_{n}^{*}\left|\hat{h}_{k}^{\mathrm{SO}}\right| \mathrm{d}_{m}^{*}\right\rangle=2^{-1} \zeta_{3 \mathrm{~d}}\left[\left\langle\mathrm{~d}_{\Gamma(n)}^{\mathrm{Cr} 1}\left|\hat{l}_{k}^{\mathrm{Cr} 1}\right| \mathrm{d}_{\Gamma(m)}^{\mathrm{Cr} 1}\right\rangle+\left\langle\mathrm{d}_{\Gamma^{\prime}(n)}^{\mathrm{Cr} 3}\left|\hat{l}_{k}^{\mathrm{Cr} 3}\right| \mathrm{d}_{\Gamma^{\prime}(m)}^{\mathrm{Cr} 3}\right\rangle\right]
$$

To work out the integrals, we express $\mathrm{Cr} 1$ - and $\mathrm{Cr} 3$-centered orbitals in two collinear reference frames with origins on $\mathrm{Cr} 1$ and $\mathrm{Cr} 3$, respectively. The axes are chosen so as to provide a natural reference frame for $\mathrm{Cr} 1$, with $z$ along $\mathrm{Cr} 1-\mathrm{X}$ and $x, y$ lying on two orthogonal X-Cr1-N planes. In the general case, rotation matrices for real spherical harmonics with $l=2^{23}$ allow to carry out the required transformation of $\mathrm{Cr} 3$-centered orbitals. In trichromium(II) strings, however, the wave functions can be worked out by simple inspection of Figure 5 . The $\mathrm{N}-\mathrm{M} \cdots \mathrm{M}-\mathrm{N}$ torsion angle defined by the two terminal metals and the $\mathrm{N}$ atoms of the same organic ligand amounts to ca. $45^{\circ}$ and the basal planes $\mathrm{Cr}_{1} \mathrm{~N}_{4}$ and $\mathrm{Cr} 3 \mathrm{~N}_{4}$ are thus twisted by ca. $45^{\circ}$ along the chain axis (the same angle is $\sim 90^{\circ}$ in pentachromium(II) string).

$$
\begin{array}{ll}
\mathrm{B}_{1} & \mathrm{~d}_{1}^{*}=2^{-1 / 2}\left(\mathrm{~d}_{x y}^{\mathrm{Cr} 1}-\mathrm{d}_{x^{2}-y^{2}}^{\mathrm{Cr} 3}\right) \\
\mathrm{E} & \left\{\begin{array}{l}
\mathrm{d}_{2}^{*}=2^{-1 / 2}\left(\mathrm{~d}_{y z}^{\mathrm{Cr} 1}-\mathrm{d}_{y z}^{\mathrm{Cr} 3}\right) \\
\mathrm{d}_{3}^{*}=2^{-1 / 2}\left(-\mathrm{d}_{x z}^{\mathrm{Cr} 1}+\mathrm{d}_{x z}^{\mathrm{Cr} 3}\right) \\
\mathrm{A}_{2}
\end{array}\right. \\
\mathrm{d}_{4}^{*}=2^{-1 / 2}\left(-\mathrm{d}_{z^{2}}^{\mathrm{Cr} 1}+\mathrm{d}_{z^{2}}^{\mathrm{Cr} 3}\right)
\end{array}
$$

The attached symmetry labels are based on $\mathrm{D}_{4}$ molecular symmetry, with the principal fourfold axis $Z$ along the metal chain and the $\mathrm{C}_{2}$ ' dyads $(X, Y)$ along the $\mathrm{Cr} 2-\mathrm{N}$ bonds with the amido nitrogens. Group theory predicts that nonzero matrix elements of the $Z$ component of orbital momentum can occur only between $\mathrm{d}_{1}^{*}$ and $\mathrm{d}_{5}^{*}$, or within the $\left(\mathrm{d}_{2}^{*}, \mathrm{~d}_{3}^{*}\right)$ pair; the $X, Y$ components can have nonzero matrix elements between the $\left(\mathrm{d}_{2}^{*}, \mathrm{~d}_{3}^{*}\right)$ pair and $\mathrm{d}_{1}^{*}, \mathrm{~d}_{4}^{*}$ or $\mathrm{d}_{5}^{*}$. The relevant matrix elements can be easily worked out starting from Eqs. (S10a-e) and Tables S5-S7, and are collected in Tables S8-S10. Equations analogous to Eqs. (S5a-c) and (S6a-c) are too cumbersome to be reported here and it is more useful to write them in general form: 


$$
\begin{aligned}
& D_{\alpha \rightarrow \alpha}(k k)=-\frac{1}{4 S^{2}} \sum_{m=1}^{4} \frac{\left|\left\langle\mathrm{d}_{5}^{*}\left|\hat{h}_{k}^{\text {SO }}\right| \mathrm{d}_{m}^{*}\right\rangle\right|^{2}}{\varepsilon^{\alpha}\left(\mathrm{d}_{5}^{*}\right)-\varepsilon^{\alpha}\left(\mathrm{d}_{m}^{*}\right)} \\
& D_{\alpha \rightarrow \beta}(k k)=\frac{1}{2 S(2 S-1)} \sum_{m, n=1}^{4} \frac{\left|\left\langle d_{n}^{*}\left|\hat{h}_{k}^{\text {SO }}\right| d_{m}^{*}\right\rangle\right|^{2}}{\varepsilon^{\beta}\left(d_{n}^{*}\right)-\varepsilon^{\alpha}\left(d_{m}^{*}\right)} \quad(n \neq m)
\end{aligned}
$$

where the required matrix elements and spin-resolved orbital energies are given in Tables S8-S10 and 8.

Table S5. On-site matrix elements $\left\langle\Psi^{\prime}\left|\hat{l}_{z}\right| \Psi\right\rangle$ between $3 \mathrm{~d}$ orbitals relevant for single-particle $\alpha \rightarrow \alpha$ and $\alpha \rightarrow$ $\beta$ spin excitations from $\Psi$ to $\Psi^{\prime}$. Elements in blue do not enter calculations and are only given for completeness.

\begin{tabular}{|c|c|c|c|c|c|}
\hline$\Psi^{\prime} \backslash \Psi$ & $\mathrm{d}_{x y}$ & $\mathrm{~d}_{x z}$ & $\mathrm{~d}_{y z}$ & $\mathrm{~d}_{z^{2}}$ & $\mathrm{~d}_{x^{2}-y^{2}}$ \\
\hline $\mathrm{d}_{x y}$ & & & & & $2 i$ \\
\hline $\mathrm{d}_{x z}$ & & & $-i$ & & \\
\hline $\mathrm{d}_{y z}$ & & $i$ & & & \\
\hline $\mathrm{d}_{z^{2}}$ & & & & & \\
\hline $\mathrm{d}_{x^{2}-y^{2}}$ & $-2 i$ & & & & \\
\hline
\end{tabular}

Table S6. On-site matrix elements $\left\langle\Psi^{\prime}\left|\hat{l}_{x}\right| \Psi\right\rangle$ between $3 d$ orbitals relevant for single-particle $\alpha \rightarrow \alpha$ and $\alpha \rightarrow$ $\beta$ spin excitations from $\Psi$ to $\Psi^{\prime}$. Elements in blue do not enter calculations and are only given for completeness.

\begin{tabular}{|c|c|c|c|c|c|}
\hline$\Psi^{\prime} \backslash \Psi$ & $\mathrm{d}_{x y}$ & $\mathrm{~d}_{x z}$ & $\mathrm{~d}_{y z}$ & $\mathrm{~d}_{z^{2}}$ & $\mathrm{~d}_{x^{2}-y^{2}}$ \\
\hline $\mathrm{d}_{x y}$ & & $-i$ & & & \\
\hline $\mathrm{d}_{x z}$ & $i$ & & & & \\
\hline $\mathrm{d}_{y z}$ & & & & $-i \sqrt{ } 3$ & $-i$ \\
\hline $\mathrm{d}_{z^{2}}$ & & & $i \sqrt{ } 3$ & & \\
\hline $\mathrm{d}_{x^{2}-y^{2}}$ & & & $i$ & & \\
\hline
\end{tabular}

Table S7. On-site matrix elements $\left\langle\Psi^{\prime}\left|\hat{l}_{y}\right| \Psi\right\rangle$ between $3 d$ orbitals relevant for single-particle $\alpha \rightarrow \alpha$ and $\alpha \rightarrow$ $\beta$ spin excitations from $\Psi$ to $\Psi^{\prime}$. Elements in blue do not enter calculations and are only given for completeness.

\begin{tabular}{|c|c|c|c|c|c|}
\hline$\Psi^{\prime} \backslash \Psi$ & $\mathrm{d}_{x y}$ & $\mathrm{~d}_{x z}$ & $\mathrm{~d}_{y z}$ & $\mathrm{~d}_{z^{2}}$ & $\mathrm{~d}_{x^{2}-y^{2}}$ \\
\hline $\mathrm{d}_{x y}$ & & & $i$ & & \\
\hline $\mathrm{d}_{x z}$ & & & & $i \sqrt{ } 3$ & $-i$ \\
\hline $\mathrm{d}_{y z}$ & $-i$ & & & & \\
\hline $\mathrm{d}_{z^{2}}$ & & $-i \sqrt{ } 3$ & & & \\
\hline $\mathrm{d}_{x^{2}-y^{2}}$ & & $i$ & & & \\
\hline
\end{tabular}


Table S8. Matrix elements $\left\langle\mathrm{d}_{n}^{*}\left|\hat{h}_{z}^{\text {SO }}\right| \mathrm{d}_{m}^{*}\right\rangle$ (in units of $\zeta_{3 \mathrm{~d}}$ ) relevant for single-particle $\alpha \rightarrow \alpha$ and $\alpha \rightarrow \beta$ spin excitations from $\mathrm{d}_{m}^{*}$ to $\mathrm{d}_{n}^{*}$. Elements in blue do not enter calculations and are only given for completeness.

\begin{tabular}{|c|c|c|c|c|c|}
\hline $\mathrm{d}_{n}^{*} \backslash \mathrm{d}_{m}^{*}$ & $\mathrm{~d}_{1}^{*}$ & $\mathrm{~d}_{2}^{*}$ & $\mathrm{~d}_{3}^{*}$ & $\mathrm{~d}_{4}^{*}$ & $\mathrm{~d}_{5}^{*}$ \\
\hline $\mathrm{d}_{1}^{*}$ & & & & & $-2 i$ \\
\hline $\mathrm{d}_{2}^{*}$ & & & $-i$ & & \\
\hline $\mathrm{d}_{3}^{*}$ & & $i$ & & & \\
\hline $\mathrm{d}_{4}^{*}$ & & & & & \\
\hline $\mathrm{d}_{5}^{*}$ & $2 i$ & & & & \\
\hline
\end{tabular}

Table S9. Matrix elements $\left\langle d_{n}^{*}\left|\hat{h}_{x}^{\text {SO }}\right| d_{m}^{*}\right\rangle$ (in units of $\zeta_{3 \mathrm{~d}}$ ) relevant for single-particle $\alpha \rightarrow \alpha$ and $\alpha \rightarrow \beta$ spin excitations from $d_{m}^{*}$ to $d_{n}^{*}$. Elements in blue do not enter calculations and are only given for completeness.

\begin{tabular}{|c|c|c|c|c|c|}
\hline $\mathrm{d}_{n}^{*} \backslash \mathrm{d}_{m}^{*}$ & $\mathrm{~d}_{1}^{*}$ & $\mathrm{~d}_{2}^{*}$ & $\mathrm{~d}_{3}^{*}$ & $\mathrm{~d}_{4}^{*}$ & $\mathrm{~d}_{5}^{*}$ \\
\hline $\mathrm{d}_{1}^{*}$ & & $i / 2$ & $i / 2$ & & \\
\hline $\mathrm{d}_{2}^{*}$ & $-i / 2$ & & & $i \sqrt{ } 3$ & $i / 2$ \\
\hline $\mathrm{d}_{3}^{*}$ & $-i / 2$ & & & & $-i / 2$ \\
\hline $\mathrm{d}_{4}^{*}$ & & $-i \sqrt{ } 3$ & & & \\
\hline $\mathrm{d}_{5}^{*}$ & & $-i / 2$ & $i / 2$ & & \\
\hline
\end{tabular}

Table S10. Matrix elements $\left\langle\mathrm{d}_{n}^{*}\left|\hat{h}_{y}^{\text {SO }}\right| \mathrm{d}_{m}^{*}\right\rangle$ (in units of $\zeta_{3 \mathrm{~d}}$ ) relevant for single-particle $\alpha \rightarrow \alpha$ and $\alpha \rightarrow \beta$ spin excitations from $\mathrm{d}_{m}^{*}$ to $\mathrm{d}_{n}^{*}$. Elements in blue do not enter calculations and are only given for completeness.

\begin{tabular}{|c|c|c|c|c|c|}
\hline $\mathrm{d}_{n}^{*} \backslash \mathrm{d}_{m}^{*}$ & $\mathrm{~d}_{1}^{*}$ & $\mathrm{~d}_{2}^{*}$ & $\mathrm{~d}_{3}^{*}$ & $\mathrm{~d}_{4}^{*}$ & $\mathrm{~d}_{5}^{*}$ \\
\hline $\mathrm{d}_{1}^{*}$ & & $i / 2$ & $-i / 2$ & & \\
\hline $\mathrm{d}_{2}^{*}$ & $-i / 2$ & & & & $-i / 2$ \\
\hline $\mathrm{d}_{3}^{*}$ & $i / 2$ & & & $i \sqrt{ } 3$ & $-i / 2$ \\
\hline $\mathrm{d}_{4}^{*}$ & & & $-i \sqrt{ } 3$ & & \\
\hline $\mathrm{d}_{5}^{*}$ & & $i / 2$ & $i / 2$ & & \\
\hline
\end{tabular}

\section{References}

(1) Armarego, W. L. F. Purification of laboratory chemicals, 5th ed.; Elsevier, Ed.; ButterworthHeinemann: Burlington, United States, 2003.

(2) Yang, M.; Lin, T.-W.; Chou, C.-C.; Lee, H.-C.; Chang, H.-C.; Lee, G.-H.; Leung, M.; Peng, S.-M. New oligo- $\alpha$-pyridylamino ligands and their metal complexes. Chem. Commun. 1997, No. 23, 22792280 .

(3) Wang, C.; Lo, W.; Chou, C.; Lee, G.; Chen, J.; Peng, S. Synthesis, Crystal Structures, and Magnetic Properties of a Series of Linear Pentanickel(II) Complexes: $\left[\mathrm{Ni}_{5}\left(\mu_{5} \text {-tpda) }\right)_{4} \mathrm{X}_{2}\right]\left(\mathrm{X}=\mathrm{Cl}^{-}, \mathrm{CN}^{-}, \mathrm{N}_{3}{ }^{-}\right.$, $\left.\mathrm{NCS}^{-}\right)$and $\left[\mathrm{Ni}_{5}\left(\mu_{5}-\mathrm{tpda}\right)_{4}\left(\mathrm{CH}_{3} \mathrm{CN}\right)_{2}\right]\left(\mathrm{PF}_{6}\right)_{2}\left(\mathrm{tpda}^{2-}=\right.$ the tripyridyldiamido dianion). Inorg. Chem. 1998, 37 (16), 4059-4065.

(4) Clérac, R.; Cotton, F. A.; Daniels, L. M.; Dunbar, K. R.; Murillo, C. A.; Pascual, I. Linear Trichromium Complexes with Direct $\mathrm{Cr}$ to Cr Contacts. 1. Compounds with $\mathrm{Cr}_{3}$ (dipyridylamide) ${ }_{4}{ }^{2+}$ Cores. Inorg. Chem. 2000, 39 (4), 748-751. 
(5) Berry, J. F.; Cotton, F. A.; Murillo, C. A.; Chan, Z.-K.; Yeh, C.-W.; Chen, J.-D. Linear Trichromium, Tricobalt, Trinickel, and Tricopper Complexes of 2,2'-Dipyridylamide. Inorg. Syn. 2014, 36, 103 110.

(6) Berry, J. F.; Cotton, F. A.; Lu, T.; Murillo, C. A.; Roberts, B. K.; Wang, X. Molecular and electronic structures by design: Tuning symmetrical and unsymmetrical linear trichromium chains. J. Am. Chem. Soc. 2004, 126 (22), 7082-7096.

(7) Wu, L.-C.; Thomsen, M. K.; Madsen, S. R.; Schmoekel, M.; Jørgensen, M. R. V.; Cheng, M.-C.; Peng, S.-M.; Chen, Y.-S.; Overgaard, J.; Iversen, B. B. Chemical Bonding in a Linear Chromium Metal String Complex. Inorg. Chem. 2014, 53 (23), 12489-12498.

(8) Chang, H.; Li, J.; Wang, C.; Lin, T.; Lee, H.-C.; Lee, G.; Peng, S. Linear Five-Centred Chromium Multiple Bonds Bridged by Four tpda ${ }^{2-}$ Ligands $\left[\operatorname{tpda}^{2-}=\right.$ tripyridyldiamido dianion] - Synthesis and Structural Studies. Eur. J. Inorg. Chem. 1999, 1999 (8), 1243-1251.

(9) Ismayilov, R. H.; Wang, W.-Z.; Lee, G.-H.; Chien, C.-H.; Jiang, C.-H.; Chiu, C.-L.; Yeh, C.-Y.; Peng, S.-M. Redox Modification of EMACs Through the Tuning of Ligands: Heptametal(II) Complexes of Pyrazine-Modulated Oligo- $\alpha$-pyridylamido Ligands. Eur. J. Inorg. Chem. 2009, 2009 (14), 2110-2120.

(10) M. Llunell, D. Casanova, J. Cirera, P. Alemany, S. A. SHAPE v2.1 - Continuous Shape Measures calculation; Universitat de Barcelona, Spain, 2013.

(11) Cotton, F. A.; Daniels, L. M.; Murillo, C. A.; Wang, X. Getting the right answer to a key question concerning molecular wires. Chem. Commun. 1999, 5 (24), 2461-2462.

(12) E04FCF, E04YCF and F02ABF, NAG Fortran Library Routines (Mark 17); NAG Ltd: Oxford, UK, 1996.

(13) Chumakova, N. A.; Yankova, T. S.; Vorobiev, A. K. EPR Study of the Orientation Distribution Function of HO2 • Radicals Ordered by Light Irradiation. Appl. Magn. Reson. 2008, 33 (1-2), 117126.

(14) Neese, F.; Solomon, E. I. Calculation of Zero-Field Splittings, g-Values, and the Relativistic Nephelauxetic Effect in Transition Metal Complexes. Application to High-Spin Ferric Complexes. Inorg. Chem. 1998, 37 (26), 6568-6582.

(15) Neese, F. Importance of Direct Spin-Spin Coupling and Spin-Flip Excitations for the Zero-Field Splittings of Transition Metal Complexes: A Case Study. J. Am. Chem. Soc. 2006, 128 (31), 1021310222 .

(16) Neese, F. Calculation of the zero-field splitting tensor on the basis of hybrid density functional and Hartree-Fock theory. J. Chem. Phys. 2007, 127 (16), 164112.

(17) Griffith, J. S. The Theory of Transition-Metal Ions; Cambidge University Press: London, 1961.

(18) Kahn, O. Molecular Magnetism; VCH-Verlag: Weinheim, 1993.

(19) Schmitt, S.; Jost, P.; van Wüllen, C. Zero-field splittings from density functional calculations: Analysis and improvement of known methods. J. Chem. Phys. 2011, 134 (19), 194113.

(20) Sugisaki, K.; Toyota, K.; Sato, K.; Shiomi, D.; Takui, T. Quasi-Restricted Orbital Treatment for the Density Functional Theory Calculations of the Spin-Orbit Term of Zero-Field Splitting Tensors. $J$. Phys. Chem. A 2016, 120 (49), 9857-9866. 
(21) Cohen, J. S.; Wadt, W. R.; Hay, P. J. Spin-orbit coupling and inelastic transitions in collisions of O(1D) with Ar, Kr, and Xe. J. Chem. Phys. 1979, 71 (7), 2955-2965.

(22) Marian, C. M. Spin-Orbit Coupling in Molecules. In Reviews in Computational Chemistry, Vol. 17; Lipkowitz, K. B., Boyd, D. B., Eds.; John Wiley \& Sons, Inc.: New York, 2001; pp 99-204.

(23) Ivanic, J.; Ruedenberg, K. Rotation Matrices for Real Spherical Harmonics. Direct Determination by Recursion. J. Phys. Chem. 1996, 100 (15), 6342-6347. 